\title{
Quantifying the Effects of Motivation on Listening Effort: A Systematic Review and Meta-Analysis
}

Peter J Carolan ${ }^{1,2}$, Antje Heinrich ${ }^{1,2}$, Kevin J Munro ${ }^{1,2}$ and Rebecca E Millman ${ }^{1,2}$

\footnotetext{
${ }^{1}$ Manchester Centre for Audiology and Deafness, School of Health Sciences, University of Manchester, Manchester, M13 9PL, UK.

${ }^{2}$ Manchester University Hospitals NHS Foundation Trust, Manchester Academic Health Science Centre, Manchester, M13 9WL, UK.
}

Financial Disclosures/Conflicts of Interest: None

Address correspondence to: Peter J. Carolan, A4.01 Ellen Wilkinson Building, Oxford Road, The University of Manchester, M13 9PL, UK.

E-mail: peter.carolan@postgrad.manchester.ac.uk

Rebecca E. Millman, B2.8 Ellen Wilkinson Building, Oxford Road, The University of Manchester, M13 9PL, UK.

E-mail: rebecca.millman@manchester.ac.uk

Orchid:

Peter J Carolan: 0000-0003-4386-0310

Antje Heinrich: 0000-0002-5940-622X

Kevin J Munro: 0000-0001-6543-9098

Rebecca E Millman: 0000-0001-8606-0167 


\section{Abstract}

Motivation influences the amount of listening effort (LE) exerted or experienced under challenging conditions, such as in high-noise environments. This systematic review and meta-analysis is the first to quantify the effects of motivation on LE. The review was preregistered in PROSPERO, and performed in accordance with PRISMA guidelines. Eligible studies examined the influence of motivation or individual traits (related to motivation) on LE in adults. Motivational factors, coded as independent variables, included financial reward, evaluative threat, perceived competence, feedback and individual traits. LE outcomes were categorised as subjective, behavioural or physiological. The quality of evidence was assessed using an adaptation of the Cochrane Collaboration Risk of Bias Tool. Nested random-effects meta-analyses were performed to quantify and compare the influence of motivational factors across LE outcomes. After assessing 3532 records, 48 studies met the inclusion criteria and 43 were included in the meta-analyses. Risk of bias was high e.g. many studies lacked sample size justification. Motivational factors had a small-to-medium effect (mean Cohen's $d=0.34$, range: $0.11-0.72$ ) on LE. When LE outcomes were considered collectively, an external manipulation of motivation (perceived competence) produced a larger mean effect size compared with individual traits. Some combinations of motivational factors and LE outcomes produced more robust effects than others, e.g. evaluative threat and subjective LE outcomes. Although wide prediction intervals and high risk of bias mean that significant positive effects cannot be guaranteed, these findings provide useful guidance on the selection of motivational factors and LE outcomes for future research.

Keywords: Effortful listening, Financial Reward, Evaluative Threat, Individual Traits, Perceived Competence 


\section{Introduction}

Listening can be effortful in adverse conditions (see Mattys et al., 2012 for a review), especially if the listener has a hearing impairment (Alhanbali et al., 2017, 2018; Hornsby, 2013; Petersen et al., 2015), and this can lead to disengagement from listening and social withdrawal (Herrmann \& Johnsrude, 2020). However, some individuals are motivated to exert listening effort (LE) under challenging conditions if the benefits outweigh the cost (Matthen, 2016). To date, the influence of motivation on LE has not been systematically reviewed and quantified.

The Framework for Understanding Effortful Listening (FUEL; Pichora-Fuller et al., 2016) defines LE as the deliberate allocation of mental resources to overcome obstacles in goal pursuit when carrying out a [listening] task and posits a role for motivation in regulating LE. The conceptual understanding of motivation outlined by FUEL builds upon Motivational Intensity Theory (MIT) (Brehm \& Self, 1989), which proposes that behavioural decisions are made on the basis of a cost-benefit analysis between the effort requirements of a task and the associated rewards. MIT predicts an interactive effect between task (listening) demands and motivation: maximal effort is invested when the listener is sufficiently motivated and listening is demanding enough to require effort but not so demanding that the effort is perceived as being wasted.

An alternative model, the Cognitive Energetics Theory (CET) (Kruglanski et al., 2012), which is intended to apply to all instances of goal-directed thinking, not only deliberate resource allocation (cf. FUEL), describes effort investment in terms of two opposing forces: a driving force towards exerting effort (based on motivation and resources) and a restraining force towards restricting effort (based on task demands and an individual's tendency to conserve resources). According to CET, individual differences in personality traits affect resource conservation and hence influence effort investment. Here we review different motivational factors and different methods of measuring LE.

\section{Categorisation of motivational factors}

Motivation refers to the energization and direction of behaviour (Elliot, 2006), i.e. motivation underlies why people decide to behave in a certain way and how intensely they conduct that behaviour. The five factors below represent different categories of motivation in experimental LE research. Four factors (financial reward, evaluative threat, perceived competence and feedback) rely on extrinsic manipulations of motivation, whereas individual traits are inherent 
to a person. How different motivational factors influence effect sizes when measuring the experience or expenditure of LE is currently unknown.

\section{- Financial reward}

Consistent with predictions of cost-benefit analysis when allocating effort, previous work suggests that financial reward can motivate participants to increase LE (e.g. (Carolan et al., 2021; Koelewijn et al., 2018; Mirkovic et al., 2019; Plain et al., 2020; Richter, 2016).

\section{- Evaluative threat}

Arousal is posited to increase the amount of resources an individual is able to allocate towards a listening task (Kahneman, 1973; Pichora-Fuller et al., 2016). Manipulations which increase arousal include evaluative threat e.g. informing participants of an upcoming performance assessment. These manipulations often include an element of social pressure e.g. in Zekveld et al. (2019) participants were informed that their data would be unusable if they failed to perform the task at a particular level. Evaluative threat may motivate greater effort investment in order to protect self-esteem from potential negative evaluations (Gendolla \& Richter, 2010). Evaluative threat has been shown to increase LE (e.g. Carrillo-de-la-Pena \& Cadaveira, 2000; Picou \& Ricketts, 2014; Zekveld et al., 2019).

\section{- Perceived competence}

Competence refers to the basic need to build skills for acting in or on the world (Dweck, 2017). Individuals may seek to maximise their performance through greater effort investment in order to demonstrate competence (Nicholls, 1984). Increasing perceived competence experimentally may increase LE, e.g. informing self-identified musicians that they should perform well on a novel auditory task because of their musical skills (McAuley et al., 2012) or that they have been specifically selected due to their qualifications (Petrie \& Carrel, 1976). Perceived competence may also be manipulated by informing participants that a listening task will be easy or hard (Hodgetts et al., 2018).

\section{- Feedback}

Participants who receive feedback are posited to increase effort to improve their performance (Kluger \& DeNisi, 1996); negative feedback highlights the gap between current behaviour and the desired goal (Burgers et al., 2015; Kluger \& DeNisi, 1996) and positive feedback enhances feelings of competence (Cusella, 1982; Henderlong \& Lepper, 2002). Generally, feedback encourages participants to set higher goals (Krenn et al., 2013; Mumm \& Mutlu, 2011) and acts as a verbal reward (Deci et al., 1999), although negative feedback 
may prompt participants to give up if they perceive the task as too difficult (Brehm \& Self, 1989). Performance feedback may influence an individual's motivation to exert LE (Gilzenrat et al., 2010).

- Individual traits

Individual traits are potentially important factors in influencing effort and performance level as they give rise to distinctive, recurrent patterns of goal selection and pursuit (Dweck, 2017; McCabe \& Fleeson, 2012; 2016). Extraversion and neuroticism may be relevant to effort regulation (Eysenck, 1990; Eysenck \& Derakshan, 2011) as these traits relate to psychological needs for affiliation and social recognition, respectively (Costa \& McCrae, 1988; John et al., 2008). Extraversion is associated with physiological differences that may affect effort regulation, e.g. lower levels of cortico-reticular arousal compared to introverts (Doucet \& Stelmack, 2000; Eysenck, 1967; Eysenck, 1990), which may lead to greater levels of effort to compensate for suboptimal arousal conditions (Brocke et al., 1996). Neuroticism may also disrupt effort regulation (Smillie et al., 2006; van Doorn \& Lang, 2010; Wallace \& Newman, 1997) by directing effort to mental processes associated with negative thoughts at the expense of task-relevant activity (Wallace \& Newman, 1997, 1998). CET (Kruglanski et al., 2012) proposes that individual traits influence the tendency to conserve resources, e.g. individuals who find mental activity enjoyable and appealing (i.e. a strong 'need for cognition') are more likely to choose resource-heavy, though potentially more successful, strategies towards goal achievement (Cacioppo \& Petty, 1982; Kruglanski et al., 2012). Previous studies suggest that extraversion (Bakan, 1959; Beauducel et al., 2006; Brocke et al., 1996; Daruna et al., 1985; Ortiz \& Maojo, 1993), neuroticism (Gale et al., 1972; Gurrera et al., 2001; Gurrera et al., 2005; Polich \& Martin, 1992; Tune, 1966; Tune et al., 2018) and the need for cognition (Enge et al., 2008; Zhang, 2017) influence LE regulation.

\section{Measures of LE}

LE may be measured using a variety of outcomes. These can be categorised as subjective (e.g. self-rated questionnaires), behavioural [e.g. performance accuracy and reaction times (RTs)] and physiological outcomes [e.g. pupillometry, cardiac reactivity, electroencephalography (EEG) and functional magnetic resonance imaging (fMRI)]. How these outcomes respond to changes in LE may depend upon the experimental context. For instance, in a rapid judgement task, an increase in effort may result in faster RTs due to increased arousal (Carrillo-de-la-Pena \& Cadaveira, 2000; Hackley \& Valle-Inclán, 1998), whereas, in other tasks, increased effort may manifest as slower RTs due to increased processing time (Marslen-Wilson \& Tyler, 1980; Pisoni \& Tash, 1974). 
When multiple LE outcomes are measured simultaneously in a within-participants design, only weak correlations are found between measures, suggesting that LE is multidimensional (Alhanbali et al., 2019; Herrmann \& Johnsrude, 2020; McMahon et al., 2016; Miles et al., 2017; Pichora-Fuller et al., 2016; Strand et al., 2018). Moreover, even if LE outcomes are within the same category, they may not relate to the same underlying processes. For instance, results from two physiological LE outcomes (pupillometry and EEG) showed differential loading in a Factor Analysis (Alhanbali et al., 2019). FUEL recommends categorising LE measures according to whether they are more responsive to listening demands, motivation or are responsive to both. Cardiac reactivity is proposed to be most sensitive to motivation, since it indexes the sympathetic nervous system (Brehm \& Self, 1989). The FUEL suggests that behavioural measures are most responsive to listening demands, while pupillometry is hypothesised to be responsive to both listening demands and motivation (Pichora-Fuller et al. 2016).

\section{Aims of the review}

This review aims to evaluate all existing studies investigating motivation and LE. Within a nested analysis, we will compare effect sizes for various motivational factors on different LE outcomes. We will also compare effect sizes within categories of LE outcomes, e.g. accuracy versus RTs for behavioural outcomes, and EEG versus pupillometry for physiological outcomes. It is unclear whether some combinations of LE outcomes and motivational factors produce more robust effects than others, e.g. physiological outcomes may measure larger effects of individual traits on LE due to the proposed biological differences underlying traits such as extraversion (Doucet \& Stelmack, 2000; Eysenck, 1967; Eysenck, 1990). This approach to systematically reviewing the existing literature will clarify the influence of motivational factors within a multidimensional construct of LE (Alhanbali et al., 2019; Herrmann \& Johnsrude, 2020; McMahon et al., 2016; Miles et al., 2017; PichoraFuller et al., 2016; Strand et al., 2018).

The review aimed to answer the following research questions (RQs):

- RQ1: What differences in effect sizes exist between different motivational factors?

- RQ2: What differences in effect sizes exist between different types of LE outcomes?

- RQ3: Which motivational factor/LE outcome combinations measure the largest/smallest effects?

\section{Methods}

Review guidelines 
The procedure and reporting of this systematic review and meta-analyses was informed by guidelines for conducting systematic reviews in healthcare, including guidance issued by the Centre for Research and Dissemination (2009), the Cochrane Handbook for Systematic Reviews (Higgins et al., 2019) and the Preferred Reporting Items for Systematic Reviews and Meta-Analyses (PRISMA) checklist (Moher et al., 2009). The protocol was registered with PROSPERO (record number: CRD42019160953) https://www.crd.york.ac.uk/prospero/display record.php?RecordID=160953.

\section{PICOS screening criteria}

The pre-registered PICOS (Population, Intervention, Comparator, Outcome, Study design) criteria (see Table 1) were used to screen all studies. Studies were initially assessed for inclusion based on their titles. P. C. carried this out independently. R. M. independently assessed $10 \%$ of study titles and there was full agreement on suitability for inclusion. 155 studies were taken forward for screening of abstracts, which was carried out by P. C.

Studies for which a decision on inclusion could not be made based on the title and abstract were screened by reading the full text. This was carried out independently by P. C. and R. $M$. In one case there was a discrepancy, which was resolved through discussion between $P$. C., R. M. and A. H.

\section{PLEASE INSERT TABLE 1 ABOUT HERE}

\section{Assessment of risk of study bias}

Risk of bias was assessed using the scoring system developed by Dryden et al. (2017). This scoring system was developed based upon risk of bias assessment for clinical trials (Higgins et al., 2011) but includes only generic criteria as reporting requirements for experimental research are generally not as rigorous as those for clinical trials. Nevertheless, it is important to highlight quality issues as these reduce the reliability of effect size estimates in metaanalyses, e.g. studies with low power may measure inaccurate or inconsistent effect sizes (see Caveats section). Table S1 shows the four risk of bias questions and the score key. These questions relate to i) sample size justification, ii) exclusion of participant data, iii) outcome reporting and iv) conflict of interest. For i) a study was deemed high risk when no power analysis was included, unclear when complete information was not provided or low risk when a full power analysis was included. For ii) studies at high risk excluded participants without providing details, posed an unclear risk when reporting exclusions was incomplete or low risk when details for excluding participants was fully reported. If no 
participants were excluded, the study was given a 'not applicable' rating. For iii) studies were deemed to be high risk when outcomes listed in the methods were not reported in the results, or unclear risk when reporting was incomplete (e.g. not including behavioural results, full statistical results or unjustified selection of a subset of parameters for a physiological outcome). Note that the research question(s) for some studies were not aligned with the aims of the present meta-analysis, which may account for bias in outcome reporting. For iv) studies with a stated conflict of interest were high risk, unclear risk where conflicts of interest were uncertain or low risk if there were no reported conflicts of interest. All studies included in the systematic review were independently assessed for risk of bias by P. C. and R. M. In all cases, it was possible to reach agreement without the need to involve an additional author. To assess risk of publication bias, a funnel plot was generated using the dmetar package (Harrer, 2019) in R (R Core Team, 2018).

\section{Search strategy}

This review considered all relevant literature published in English to $23^{\text {rd }}$ February 2021. This included research published in peer-reviewed journals, conference papers/proceedings containing research data, book chapters, dissertations and theses. A systematic search of the databases PubMed, Web of Science, Scopus, PsycINFO and Google Scholar was carried out. Search terms related to "listening effort", "motivation" and "personality" were entered into the title, abstract and keyword fields (see Table S2 for detailed search criteria). The search criteria were modified after registering with PROSPERO to exclude studies containing "children" in the title. After performing the search, records were transferred to Endnote and then Microsoft Excel for screening.

Meta-analysis strategy

Cohen's $d$ was used as an effect size metric, which represents the standardized mean difference score in LE between high and low motivation conditions (either repeatedmeasures or between-groups comparisons). A positive Cohen's $d$ represents an increase in LE in response to motivation. Effect sizes were calculated directly using means, standard deviations and the sample size where this information was provided by the author(s). Where this was not possible $F$ ratios, $t$ tests or correlation coefficients were used. For seven studies (Asbjörnsen et al., 1992; Bijleveld et al., 2009; DeWall et al., 2011; Ditraglia \& Polich, 1991; Hodgetts et al., 2018; Mirkovic et al., 2019; Picou \& Ricketts, 2014), means and standard deviations were estimated from figures using WebPlotDigitizer (Rohatgi, 2020). Where insufficient information was included in published articles, attempts were made to contact the author(s) for further information. Where studies had "easy" and "hard" listening 
demands (or other task difficulty manipulations), the effect size was based on the interactive effect between listening demands and motivation. If this information was not provided by the author(s), the effect size for the most demanding listening condition was used. This approach was necessary as i) there may be null results for low-demand conditions due to low LE requirements, and ii) the effect of motivation on LE is posited to be greater for higher listening demands (Brehm \& Self, 1989). Signs of effect sizes were reversed for the individual trait neuroticism as higher neuroticism was expected to lower LE (see Categorisation of motivational factors: Individual traits). As RTs may feasibly accelerate or decelerate with greater effort (see Measures of LE), the absolute value of the effect size was taken for RTs.

The Measure of the Effect (MOTE) package (Buchanan et al., 2017) in R (R Core Team, 2018) was used to calculate effect sizes and 95\% confidence intervals (Cl) for each study. For repeated-measures studies, the following equation (adapted from Lakens, 2013) was used to calculate Cohen's $d$ :

$$
d_{r m}=\frac{M_{1}-M_{2}}{\sqrt{\left(S D_{1}^{2}+S D_{2}^{2}\right)-\left(2 x r \times S D_{1} \times S D_{2}\right)}} x \sqrt{2 \times(1-r)}
$$

Where $M_{1}$ and $M_{2}$ refer to the means for each motivation condition, $S D_{1}$ and $S D_{2}$ are the standard deviation of the mean for the unmotivated and motivated conditions, respectively, and $r$ is the Pearson's correlation coefficient between conditions. Where the correlation coefficient was not provided (as is often the case in experimental designs), the methods outlined by Hullett \& Levine (2003) were used to estimate the correlation coefficient from the $t$-statistic $(t)$ and $F$-statistic $(F)$ (where $d f_{\text {error }}$ is the degrees of freedom for the error term):

$$
\begin{aligned}
& r=\sqrt{\frac{t^{2}}{t^{2}+d f}} \\
& r=\sqrt{\frac{F}{F+d f_{\text {error }}}}
\end{aligned}
$$

If $F$ and $t$ were not provided, an alternate equation (Cumming \& Calin-Jageman, 2017), which does not require the correlation coefficient, was used to calculate Cohen's $d$ (where $M_{\text {diff }}$ is the difference in the means between motivation conditions):

$$
d_{a v}=\frac{M_{\text {diff }}}{\left(\frac{S D_{1}+S D_{2}}{2}\right)}
$$


The following formula (Rosenthal, 1991) was used to calculate Cohen's $d$ from $t$ where means were unavailable for repeated-measures studies (where $n$ is the sample size):

$$
d_{z}=\frac{t}{\sqrt{n}}
$$

For between-groups studies, Cohen's $d$ was calculated as follows (Cumming, 2012) (where $S D_{\text {pooled }}$ is the pooled standard deviation):

$$
d_{s}=\frac{M_{\text {diff }}}{S D_{\text {pooled }}}
$$

Where means were not available, the formula adapted from Lakens (2013) was used (where $N$ is the sample size):

$$
d_{s}=\frac{t}{\sqrt{N}}
$$

For studies involving correlations, the 95\% Cl for Pearson's correlation coefficients were calculated using the Meta-Essentials workbook (Suurmond et al., 2017). To aid comparison with other studies, these values were converted to Cohen's $d$ using a web-based effect size calculator (Lenhard \& Lenhard, 2016).

A random-effects meta-analysis was carried out using the Meta package (Schwarzer, 2007) in $R$ (R Core Team, 2018). Due to potential covariates not considered here (e.g. participants hearing level), a random-effects rather than a fixed-effects meta-analysis model was applied (Thompson \& Higgins, 2002). A summary effect size (Cohen's $d$ ), 95\% Cl around this effect size, $Z$-statistic and $p$-value were calculated to provide a test of whether the summary effect size differed significantly from zero. The inconsistency measure, $l^{2}$, and its $95 \% \mathrm{Cl}$ was calculated as a measure of heterogeneity, expressed as a percentage (Higgins et al., 2019). Prediction intervals (PIs) were calculated using the Hartung-KnappSidik-Jonkman method (Hartung \& Knapp, 2001; Sidik \& Jonkman, 2003) within the Meta package (Schwarzer, 2007).

In order to address the individual research questions, a nested approach to data analysis was taken: Subgroup analyses using random-effects models were performed using the Meta package (Schwarzer, 2007) and effect sizes, 95\% Cls, Z-statistics, $p$-values, $P^{2}$ and Pls for subgroups were calculated. Apart from subgroup analysis $E$ which explored the effect of financial reward on LE (discussed below), all analyses included at least 10 observations, which is considered the minimum for performing this type of analysis (Higgins et al., 2019). 
Motivational factors were grouped into 5 categories: financial reward, perceived competence, feedback, evaluative threat and individual traits (see Categorisation of motivational factors). Outcomes of LE studies were categorised as subjective, behavioural or physiological (see Measures of LE).

Seven sets of meta-analyses were conducted:

- First, a meta-analysis of all studies was carried out to determine the overall effects of motivational factors on LE outcomes.

- To address RQ1, which asked whether there are differences in LE dependent upon the type of motivational factor, we conducted subgroup analysis A (see Table 3) to compare effect sizes of motivational factors on all LE outcomes.

- RQ2 asked whether effect sizes differ depending upon the type of LE outcome measure (i.e. subjective, behavioural or physiological) and whether certain exemplars of LE outcome measurement categories capture larger effects than others. Subgroup analysis B (see Table 5) compared the effect sizes captured using different types of LE outcomes.

- Subgroup analyses $C$ and D (see Table 5) compared effect sizes for specific behavioural and physiological measures. An insufficient number of outcomes (i.e. fewer than 10 observations) precluded a subgroup analysis of subjective measures.

- Finally, to address RQ3, which asked which combinations of motivational factors/LE outcomes produced the largest/smallest effects, a series of subgroup analyses were carried out (subgroup analyses E to G) (see Table 6) comparing effect sizes for different types of LE outcomes for specific motivational factors.

An alpha level of .05 was used throughout, except for post-hoc analyses where a Bonferroni adjustment was made for the number of comparisons. For post-hoc analyses, the dmetar package (Harrer, 2019) in R (R Core Team, 2018) was used to test for differences in effect sizes between subgroups in a random-effects model, following the procedure of Borenstein and Higgins (2013) to calculate a $Q$ statistic and its associated $p$-value. These analyses included only two categories of interest (e.g. individual traits and perceived competence to compare effect sizes for specific motivational factors).

\section{Results}

Screening results 
Figure 1 shows the PRISMA flowchart for the literature search. The search returned 4,639 studies. After removing duplicates, 3,504 studies remained. After screening titles and abstracts, the full text of 64 studies were assessed for eligibility. An additional 28 studies were sourced by checking the reference list of studies selected for full-text screening and checking citations to these studies. After screening the full text of the total 92 studies, 44 studies were excluded: 19 were excluded because studies did not include an LE outcome, 19 did not manipulate motivation or measure personality traits, 3 did not manipulate motivation or measure LE, 1 was a qualitative study, 1 study used visual rather than auditory stimuli and 1 study combined results for an auditory task with results from a visual task. Forty-eight studies were eligible for inclusion in the review. A summary of the 48 included studies is provided in Table 2. This summary includes sample size, demographic information (ages, hearing status), details of the stimuli used, motivation manipulation/personality trait considered, listening demand manipulations and main findings for each LE outcome.

Of the 48 included studies, only 43 of these studies were suitable for inclusion in the meta-analysis (see Meta-analysis strategy). Four articles (Cahill \& Polich, 1992; Cox et al., 1999; Pritchard, 1989; Sewell, 1985) did not provide relevant data to be included with the meta-analysis. A further study (Beatty et al., 1980) was not included in the meta-analysis as this study involved the use of course credit for students as a performance-based reward, rather than financial reward. Included studies often contained multiple outcome measures, leading to a total of 187 outcomes from 43 studies that were included in the meta-analysis.

\section{PLEASE INSERT FIGURE 1 ABOUT HERE PLEASE INSERT TABLE 2 ABOUT HERE}

\section{Risk of bias assessment}

The results of the overall risk of bias assessment are displayed in Figure 2. A breakdown of scores for individual studies is included in the supplemental materials (see Table S3). The vast majority of the studies did not include a sample size justification, presenting a high risk of bias. The majority of studies either did not exclude any participants or gave adequate justification for exclusion, presenting a low risk of bias. Reporting of outcomes presented a high risk of bias for $\sim 20 \%$ of the studies, and there were some concerns for $\sim 50 \%$. Bias related to outcome reporting may have been present for the following reasons: statistical analyses were not reported for some outcomes, behavioural data were missing from the results, or physiological data were not fully reported. Some studies did not justify conducting analyses on subgroups of participants only. No studies reported conflicts of interest (Q4). 
The funnel plot of effect sizes (see Figure S1) is roughly symmetrical, suggesting no publication bias.

\section{PLEASE INSERT FIGURE 2 ABOUT HERE}

\section{Qualitative synthesis}

Five studies were not included in the meta-analyses (see Screening results for details). The influence of motivation on LE in these studies was mixed.

Beatty et al. (1980) compared comprehension of a lecture about computer music in students who were, or were not, offered performance-based course credit as a reward. They found significantly greater comprehension for students in the reward compared to no reward group but no significant listening demand/reward group interaction. Sewell (1985) compared listening comprehension of a "scholarly speech" between students who were told the speech would be similar to other classroom lectures ("boring") or that the speech was on an interesting and relevant topic ("interesting"). Some participants in the interesting group were also offered a financial reward for achieving high levels of listening comprehension (>90\%). The effect of group and financial reward was not statistically significant.

Cahill and Polich (1992) compared event-related potential (ERP) components of "extreme groups" of introverts and extraverts during an auditory discrimination task (tones). The listening task contained four difficulty conditions, based upon the probability of the presentation of the target stimulus. The P3 amplitude showed a significant effect of the interaction between personality, probability and gender. No effects were observed for P3 latency. Using a similar auditory discrimination task, Pritchard (1989) found i) a significant correlation between P3 amplitude and scores on the Lie scale of the Eysenck Personality Questionnaire and ii) a significant negative correlation between P3 latency and the Neuroticism scale of the Eysenck Personality Questionnaire. These effects were seen in male but not female participants; combined results were not reported.

Cox et al. (1999) investigated personality traits and self-reported ease of communication in adult hearing aid users. Extraversion-introversion and locus of control did not predict ease of communication when participants were aided or unaided. Extraversionintroversion predicted the change scores (i.e. difference between unaided and aided ratings), accounting for $9.5 \%$ of the variance.

\section{Meta-Analyses}

Meta-analysis of motivational factors on all LE outcome measurements

A meta-analysis of all studies was conducted to determine the effect of motivational factors (collectively) on all LE outcomes. The results revealed an overall positive effect (i.e. LE 
increased with greater motivation). The random-effects model predicted a small-tomoderate effect size of $d=.34(95 \% \mathrm{Cl}=[.28, .40], Z=17.75, \mathrm{PI}=[-.30, .99] p<.001)$. Note that heterogeneity was in the moderate-to-high range for the majority of nested analyses (see Tables 3-6).

\section{The influence of motivational factors}

Table 3 shows the results of subgroup analysis A, which compared the effects of motivational factors on each LE outcome. The type of motivational factor significantly influenced $\operatorname{LE}(Q(3)=11.91 ; p=.008, \mathrm{PI}=[-.33,1.00])$. To investigate the significant effect of motivational factor type, post-hoc analyses were carried out (see Table 4 and Figure 3). A significantly smaller effect size for individual traits was found when compared to perceived competence $(Q(1)=8.81, p=.003)$. Trends towards smaller effect sizes for individual traits were also found when compared to financial reward $(Q(1)=2.97, \mathrm{p}=.084)$ and evaluative threat $(Q(1)=3.07, p=.080)$, and financial reward compared to perceived competence $(Q(1)=3.55, p=.059)$. No other post-hoc comparisons were significant.

\section{PLEASE INSERT TABLE 3 ABOUT HERE \\ PLEASE INSERT TABLE 4 ABOUT HERE \\ PLEASE INSERT FIGURE 3 ABOUT HERE}

\section{The influence of LE outcome measurement}

Table 5 shows the results of subgroup analysis $B$, which investigated the influence of LE outcome type. While a positive effect of motivation on LE was found for every LE outcome, the size of the effect did not differ between outcomes $(Q(2)=1.92 ; p=.383, \mathrm{PI}=[-.33, .99])$. The results of subgroup analysis $C$, which compared effect sizes for specific behavioural measures, are reported in Table 5. Motivation had a similar-sized small effect, regardless of whether studies measured LE as performance accuracy or RTs $(Q(1)=.01, p=.911, \mathrm{PI}=[-$ $.38, .97])$. Table 5 also shows the results of subgroup analysis $D$, which compared effect sizes for specific physiological outcomes. Again, motivation had a similar-sized small positive effect when LE was measured using EEG or pupillometry $(Q(1)=.11, p=.743, \mathrm{PI}=$ $[-.24, .92])$.

\section{Nested analyses for specific motivational factors comparing types of LE outcomes}

Table 6 shows the results of subgroup analyses used to address RQ3, which asked whether there are differences in effect sizes for different combinations of motivational factors and LE outcomes. Subgroup analysis E (Table 6) compared effect sizes measured with different 
types of LE outcomes when studies operationalised motivation as financial reward. This analysis showed significant positive effect sizes for studies using behavioural $(d=.34,95 \%$ $\mathrm{Cl}=[.16, .52], Z=3.66, p<.001, \mathrm{PI}=[-.39,1.06])$, physiological $(d=.58,95 \% \mathrm{Cl}=[.37$, $.80], Z=5.35, p<.001, \mathrm{PI}=[-.24,1.41])$ and subjective measures $(d=.11,95 \% \mathrm{Cl}=[-.10$, $.32], Z=1.05, p=.03, \mathrm{PI}=[-.19, .41])$. When motivation was operationalised as financial reward, there was a significant difference in effect sizes depending upon the type of LE outcome $(Q(2)=9.53, p=.009, \mathrm{PI}=[-.29,1.09])$. To investigate the source of this difference, post-hoc analyses were carried out to compare effect sizes measured by each type of LE outcome (see Table 7 and Figure 4). A significantly smaller effect of financial reward was found for physiological measures of LE when compared to subjective measures $(Q(1)=9.53, p=.002)$.

Subgroup analysis $F$ (Table 6) compared effect sizes measured with different types of LE outcomes for studies investigating individual traits. Subjective outcomes were not included in this analysis due to limited numbers of eligible studies. All types of LE outcomes captured positive effects, but the size of the effect depended upon the type of LE outcome $(Q(1)=5.91, p=.020, \mathrm{PI}=[-.34, .89]):$ a significantly greater effect was seen for physiological $(d=.34,95 \% \mathrm{Cl}=[.25, .44], Z=7.05, p<.001, \mathrm{PI}=[-.29, .98])$ compared to behavioural $(d=.15,95 \% \mathrm{Cl}=[.03, .27], Z=2.46, p=.014, \mathrm{PI}=[-.44, .74])$ outcomes.

Finally, subgroup analysis $\mathrm{G}$ (Table 6 ) considered studies operationalising motivation as evaluative threat. Due to limited numbers of eligible studies, behavioural outcomes were omitted from this analysis. Again, positive effects were captured using all types of LE outcomes, but the type of LE outcome influenced the size of the effect $(Q(1)=7.42, p=$ $.006, \mathrm{PI}=[-.16,1.01]):$ a significantly greater positive effect was seen for subjective $(d=.72$, $95 \% \mathrm{Cl}=[.43,1.01], Z=1.61, p<.001, \mathrm{PI}=[-.15,1.59])$ compared to physiological outcomes $(d=.24,95 \% \mathrm{Cl}=[.07, .38], Z=2.88, p=.004, \mathrm{PI}=[-.18, .65])$.

\section{PLEASE INSERT TABLE 6 ABOUT HERE \\ PLEASE INSERT TABLE 7 ABOUT HERE \\ PLEASE INSERT FIGURE 4 ABOUT HERE}

\section{Discussion}

A systematic review and meta-analysis was carried out to quantify the relationship between motivational factors and types of LE outcomes for the first time. We used random-effects meta-analyses with subgroups to investigate differences in effect sizes for different 
motivational factors and types of LE outcomes on the expenditure or experience of LE. When LE outcomes were considered collectively, nested analyses showed differences in effect sizes for motivational factors (perceived competence cf. individual traits). When all motivational factors were combined, similar effect sizes were measured using subjective, behavioural and physiological LE outcomes. Comparisons of specific exemplars of LE outcome measurements (where permitted due to study numbers) revealed similar effect sizes. However, for certain motivational factors (financial reward, individual traits and evaluative threat), the type of LE outcome influenced the size of the measured effect.

\section{Quality of evidence}

The risk of bias was generally high due to lack of sample size justification. Concerns were also raised about missing or incomplete outcome reporting. These quality issues reduce confidence in the effect sizes presented here.

\section{The influence of motivational factors on $L E$}

The primary meta-analysis (which considered all motivational factors and all LE outcomes) suggested that listeners expended or experienced greater effort if motivation was high. This supports a role of motivation in the allocation of resources to listening tasks, as outlined by several models and frameworks e.g. FUEL (Pichora-Fuller et al., 2016), MIT (Brehm \& Self, 1989), CET (Kruglanski et al., 2012) and the Model of Listening Engagement (Herrmann \& Johnsrude, 2020).

In our meta-analysis, all motivational factors showed positive effects on LE outcomes. This result may have occurred because these motivational factors increase LE investment by appealing to basic psychological needs (Dweck, 2017). Need-press theory (Murray, 1938) predicts that environmental factors, or "presses", influence how psychological needs regulate behaviour. The motivational factors considered in this review may activate different underlying needs, e.g. financial reward and perceived competence may "press" upon needs in the domains of materialism and human power, respectively, leading to increased LE. Individual traits are also posited to be related to underlying psychological needs, which give rise to characteristic styles of goal pursuit (Dweck, 2017).

Studies operationalising motivation as individual traits captured significantly smaller effect sizes compared to extrinsic manipulations of motivation i.e. perceived competence. As variability in individual traits within participant samples can be low, some of the studies (Beauducel et al., 2006; Brocke et al., 1996; Cahill \& Polich, 1992; Daruna et al., 1985; Ditraglia \& Polich, 1991; Enge et al., 2008; Ortiz \& Maojo, 1993; Rammsayer \& Stahl, 2004; Schmidt et al., 2004; Tune, 1966) compared participants at the extreme ends of the 
distribution (usually those scoring in the upper and upper lower quartiles). This procedure is commonly used within personality research to increase statistical power (see Preacher et al., 2005 for discussion of the strengths and limitations of this approach). For researchers interested in the connection between motivational trait differences and LE, an extreme group procedure is worth considering to increase the likelihood of producing robust results.

\section{The influence of outcome selection on $L E$}

An overall positive effect of motivational factors was detected using subjective, behavioural and physiological LE outcome measurements, with no significant differences in effect sizes between outcome types. However, there may be differences in sensitivity to motivation for the different types of LE outcomes which are not apparent in the subgroup analyses presented here due to the broad categorisation of subjective, behavioural or physiological LE outcomes. The inclusion of different measures within the same LE outcome domain may contribute to the high heterogeneity in the subgroup analyses (see Caveats).

Finer-grained comparison was limited due to the small numbers of studies, however, we were able to compare effects measured using two behavioural (RT and performance accuracy) and two physiological LE outcomes (pupillometry and EEG). Motivation produced a similar-sized small increase in LE when measured by either performance accuracy or RTs. The FUEL posits that when an individual's resource capacity is under strain or exceeded, performance errors and a reduction in processing speed may occur, which can allow inferences about LE. The FUEL also notes that RTs are not a process pure measure (Pichora-Fuller et al., 2016) as they may also index other aspects of cognition such as memory. Some authors, however, consider performance accuracy to be a measure of achievement rather than effort (Gendolla \& Richter, 2010): in some LE studies performance accuracy remains stable while RTs slow with greater listening demands (Sarampalis et al., 2009; Strand et al., 2020). The divergence in these results suggests a theoretical distinction between performance effectiveness (i.e. quality of task performance) and processing efficiency (effectiveness in relation to effort) (Eysenck \& Calvo, 1992). Therefore, although similar sized positive effects were measured with both performance accuracy and RTs, these outcomes may not necessarily index the same LE construct.

Similar positive effect sizes were also measured using pupillometry and EEG. Pupillometry and EEG are proposed to index changes in the autonomic and central nervous system related to LE, respectively (Pichora-Fuller et al., 2016). Due to a limited number of outcomes in the included studies, only these two specific physiological measures could be compared in the present study. Notably, a few studies found physiological effects of motivation (change in pupil size or cardiac response) in the absence of behavioural and/or 
subjective effects (Koelewijn et al., 2018; Richter, 2016). Increased physiological arousal may reflect the 'cost' required to maintain performance under increased task demands (Kahneman, 1973). However, concurrent changes in behavioural and/or subjective measures would increase confidence that the physiological changes reflect the influence of motivation on LE as physiological measures of LE may index multiple processes. For example,. Zekveld et al. (2018) discuss the sensitivity of the pupil dilation response to various task manipulations and intra-individual differences.

\section{Combinations of motivational factors and types of $L E$ outcomes influence $L E$ effect sizes}

Subgroup analyses investigated combinations of motivational factors and types of LE outcomes. These analyses revealed significant differences in effect sizes for financial reward, evaluative threat and individual traits, depending upon the type of LE outcome. These differential effects may help inform research planning decisions when investigating motivation and LE. For instance, if researchers are interested in the effect of evaluative threat on LE, using subjective rather than physiological measures would be advisable, based on the results of the meta-analyses presented here. When investigating individual traits or financial reward, physiological measures may be optimal compared with subjective and behavioural measures, respectively. However, note that the effect size associated with subjective measures was based on only six outcomes. At least 10 observations are recommended for subgroup analyses (Higgins et al., 2019). However, 10 observations would be insufficient if covariates are distributed unevenly across studies and, in general, subgroup analyses should be interpreted cautiously where the number of observations is low (Higgins et al., 2019). Although certain combinations of motivational traits/LE outcomes may produce bigger effect sizes than others, it is important to note that PIs encompassed zero for all factor/outcome type combinations and therefore null or negative effects may be observed in future studies.

Differences in effect sizes are consistent with the notion that LE is a multi-factorial construct (Alhanbali et al., 2019; Herrmann \& Johnsrude, 2020; Hughes et al., 2018; McMahon et al., 2016; Pichora-Fuller et al., 2016; Strand et al., 2018; Strauss \& Francis, 2017). However, here we quantified differences between types of LE outcomes only when considering specific motivational factors. Particular types of LE outcomes may be sensitive to certain motivational factors for several reasons. For example, biological differences may underlie trait behaviours, e.g. relative to introverts, extraverts are suggested to have lower levels of cortical arousal (Eysenck, 1967) and this may explain why larger effect sizes were measured for individual traits using physiological outcomes. The finding of larger effect sizes for subjective compared to physiological LE outcomes, when motivation is 
operationalised as evaluative threat, may be due to the small number of studies that used cardiac reactivity to measure LE: cardiac reactivity is posited to be particularly sensitive to increases in effort due to fear of social evaluation (Gendolla \& Richter, 2010). The large effect size for subjective LE outcomes suggests that evaluative threat elicits a range of effort-related listening experiences, as the studies included in the meta-analysis used questions gauging effort, likelihood of quitting and desire to control the situation (Picou \& Ricketts, 2014; Zekveld et al., 2019). However, evaluative threats may increase anxious thoughts which can occupy working memory (Eysenck et al., 2007; Putwain et al., 2014) and effortful listening may rely on working memory capacity (Rönnberg et al., 2019). High levels of anxiety may lead to reduced processing capacity for the task at hand and result in poorer performance (Eysenck \& Calvo, 1992; Eysenck et al., 2007).

\section{Caveats}

Heterogeneity was in the moderate-to-high range for the subgroup analyses included in this systematic review. Inconsistency measures of $25 \%, 50 \%$ and $75 \%$ are usually interpreted as low, moderate and high levels of heterogeneity, respectively (Higgins \& Thompson, 2002). The high levels of heterogeneity in the meta-analyses presented here are comparable with other systematic reviews of experimental psychology research (e.g. Rung and Madden, (2018); Hirst et al., (2018). Within audiology research, a meta-analysis of experimental studies investigating whether probe-tube verification of real-ear hearing aid amplification characteristics improves outcomes in adults identified high heterogeneity $(R$ : $61-100 \%$ ) for a number of subgroup analyses (Almufarrij et al., Accepted/In press). Heterogeneity in the present analysis may have arisen due to between-study differences in participant characteristics (age, gender, hearing level etc.), variation in the operationalisation of listening demands (e.g. single or dual tasks, vocoded speech or speech presented in a noise background) and stimulus complexity (e.g. tones, digits or spoken sentences). There is also variation in how motivational factors were operationalised within each category. For instance, studies using financial reward to motivate participants offered different amounts of financial reward e.g. in the high motivation condition Bijleveld et al. (2009) offered 50 Euros, Koelewijn et al. (2018) offered 5 Euros. Some studies compared effects of 'high' and 'low' levels of financial reward (Asbjörnsen et al., 1992; Bijleveld et al., 2009; Carolan et al., 2021; Kahneman \& Peavler, 1969; Kahneman et al., 1968), other designs compared a financial reward condition to a no financial reward condition (Kang et al., 2017; Snyder \& Snyder, 1956) or required strategic allocation of LE to maximise reward (Gilzenrat et al., 2010; Zhang, 2017; Zhang et al., 2019). 
As the practical implications of the observed heterogeneity, expressed as $P$, are not always clear, we also calculated Pls, which show the range of effect sizes that researchers can expect when planning future studies using similar paradigms to those included in the meta-analysis. Where there is substantial heterogeneity in a meta-analysis, the prediction interval has a wider range than the $95 \% \mathrm{Cl}$ of the standardised mean difference; thus it may be misleading to only present the standardised mean difference and its $\mathrm{Cl}$, since the Pls may reveal potential values on both sides of the null (IntHout et al., 2016). All the PIs in the present meta-analysis contained values on both sides of the null, thus inconsistent results are possible using the same motivational factor/LE outcome. For example, this could explain why Richter (2016) found a significant increase in LE measured using cardiac reactivity (preejection period, PEP) when participants were offered performance-based financial reward, while Plain et al. (2020), found null results for the effects of financial reward on PEP reactivity.

As discussed above, the majority of studies in this review did not include a power analysis. Regardless of the size of a statistical effect, the occurrence of both type $S$ and type M errors is substantially inflated when statistical power is low (Gelman \& Carlin, 2014). A type S error is the probability that the estimated effect has the wrong sign, i.e. that the estimate indicates a positive effect when in fact the true effect is negative or vice versa (Kirby \& Sonderegger, 2018). Type S errors may explain inconsistencies within the literature for some measures, e.g. these errors may account for the differential effects of motivation on RTs reported in the included studies (Carolan et al., 2021; Carrillo-de-la-Pena \& Cadaveira, 2000; Kang et al., 2017; Strand et al., 2018; Weis et al., 2013). A type M error is the extent to which the magnitude of an effect of interest is exaggerated, based on the estimated effect size of the study. It is possible that type M errors may account for outliers in the metaanalyses (see Figure S1). We therefore urge researchers in the field to ensure that future studies of the effects of motivation on LE are adequately powered and that the results of power calculations are fully reported.

The effect of motivation is proposed to be greatest when tasks are demanding (Brehm \& Self, 1989). If listening is perceived to be too difficult then participants may decide to disengage, which may have impacted upon the results of the meta-analyses presented here: we decided to include either an effect size for the interaction, or if not available, the effect size from the most demanding conditions, when studies utilised multiple listening demand conditions (see Methods: Meta-analysis strategy).

\section{Conclusion}

All motivational factors considered here, in the first meta-analysis of motivation and LE, increased the experience and/or exertion of LE. Therefore it is therefore important to 
consider motivational context when designing and interpreting LE studies. External manipulations of motivation (e.g. perceived competence) elicited more robust effect sizes compared to individual traits. For certain motivational factors (individual traits, evaluative threat, financial rewards), effect sizes were dependent upon LE outcome measurement. Further research into the relationship between motivation and LE should be guided by this review, which, for the first time, highlights combinations of LE outcomes and motivational factors that are likely to produce the most robust effects on LE.

\section{Acknowledgments}

This work was supported by the NIHR Manchester Biomedical Research Centre (BRC-121520007). The authors thank the corresponding authors of the studies for sharing data not reported in the publications and for responding to our queries.

\section{Declaration of Conflicting Interests}

The authors declared no potential conflicts of interest with respect to the research, authorship, and/or publication of this article. 


\section{References}

Alhanbali, S., Dawes, P., Lloyd, S., \& Munro, K. J. (2017). Self-reported listening-related effort and fatigue in hearing-impaired adults. Ear and Hearing, 38(1), 39-48. doi: 10.1097/Aud.0000000000000361

Alhanbali, S., Dawes, P., Lloyd, S., \& Munro, K. J. (2018). Hearing Handicap and Speech Recognition Correlate With Self-Reported Listening Effort and Fatigue. Ear and Hearing, 39(3), 470-474. doi: 10.1097/Aud.0000000000000515

Alhanbali, S., Dawes, P., Millman, R. E., \& Munro, K. J. (2019). Measures of listening effort are multidimensional. Ear and Hearing, 1084-1097. doi: 10.1097/AUD.0000000000000697

Almufarrij, I., Dillon, H., \& Munro, K. (Accepted/In press). Does probe-tube verification of real-ear hearing aid amplification characteristics improve outcomes in adults? A systematic review and meta-analysis. . Trends in Hearing (Online).

Asbjörnsen, A., Hugdahl, K., \& Bryden, M. P. (1992). Manipulations of subjects' level of arousal in dichotic listening. Brain and Cognition, 19(2), 183-194. doi: 10.1016/02782626(92)90044-M

Bakan, P. (1959). Extraversion-Introversion and Improvement in an Auditory Vigilance Task. British Journal of Psychology, 50(4), 325-332. doi: 10.1111/j.20448295.1959.tb00711.x

Beatty, M. J., Behnke, R. R., \& Froelich, D. L. (1980). Effects of achievement incentive and presentation rate on listening comprehension. Quarterly Journal of Speech, 66(2), 193-200. doi: 10.1080/00335638009383515

Beauducel, A., Brocke, B., \& Leue, A. (2006). Energetical bases of extraversion: Effort, arousal, EEG, and performance. International Journal of Psychophysiology, 62(2), 212-223. doi: 10.1016/j.jpsycho.2005.12.001

Bijleveld, E., Custers, R., \& Aarts, H. (2009). The unconscious eye opener: pupil dilation reveals strategic recruitment of resources upon presentation of subliminal reward cues. Psychological science, 20(11), 1313-1315. doi: 10.1111/j.14679280.2009.02443.x

Borenstein, M., \& Higgins, J. P. T. (2013). Meta-Analysis and Subgroups. Prevention Science, 14(2), 134-143. doi: 10.1007/s11121-013-0377-7

Brehm, J. W., \& Self, E. A. (1989). The intensity of motivation. Annual Review of Psychology, 40, 109-131. doi: 10.1146/annurev.ps.40.020189.000545

Brocke, B., Tasche, K. G., \& Beauducel, A. (1996). Biopsychological foundations of extraversion: Differential effort reactivity and the differential P300 effect. Personality and Individual Differences, 21(5), 727-738. doi: 10.1016/0191-8869(96)00117-1

Buchanan, E., Scofield, J., \& Valentine, K. D. (2017). MOTE: Effect Size and Confidence Interval Calculator (Version 1.0.2).

Burgers, C., Eden, A., Engelenburg, M., \& Buningh, S. (2015). How feedback boosts motivation and play in a brain-training game. Computers in Human Behavior, 48, 94103. doi: $10.1016 /$ j.chb.2015.01.038

Cacioppo, J. T., \& Petty, R. E. (1982). The need for cognition. Journal of Personality and Social Psychology, 42(1), 116-131. doi: 10.1037/0022-3514.42.1.116

Cahill, J. M., \& Polich, J. (1992). P300, probability, and introverted/extroverted personality types. Biological Psychology, 33(1), 23-35. doi: 10.1016/0301-0511(92)90003-D

Carolan, P. J., Heinrich, A., Munro, K. J., \& Millman, R. E. (2021). Financial reward has differential effects on behavioural and self-report measures of listening effort. International Journal of Audiology, 1-11. doi: 10.1080/14992027.2021.1884907

Carrillo-de-la-Pena, M. T., \& Cadaveira, F. (2000). The effect of motivational instructions on P300 amplitude. Clinical Neurophysiology, 30(4), 232-239. doi: 10.1016/s09877053(00)00220-3

Centre for Research and Dissemination. (2009). Systematic Reviews: CRD's Guidance for Undertaking Reviews in Healthcare. York, England: Centre for Reviews \& Dissemination. 
Costa, P. T., \& McCrae, R. R. (1988). Personality in adulthood: A six-year longitudinal study of self-reports and spouse ratings on the NEO Personality Inventory. Journal of Personality and Social Psychology, 54(5), 853-863. doi: 10.1037/0022-3514.54.5.853

Cox, R. M., Alexander, G. C., \& Gray, G. (1999). Personality and the subjective assessment of hearing aids. Journal of the American Academy of Audiology, 10(1), 1-13.

Cumming, G. (2012). Understanding the New Statistics: Effect Sizes, Confidence Intervals and Meta-analysis. New York: Routledge.

Cumming, G., \& Calin-Jageman, R. (2017). Introduction to the New Statistics: Estimation, Open Science, and Beyond: Routledge.

Cusella, L. P. (1982). The effects of source expertise and feedback valence on intrinsic motivation. Human Communication Research, 9(1), 17-32. doi: 10.1111/j.14682958.1982.tb00680.x

Daruna, J. H., Karrer, R., \& Rosen, A. J. (1985). Introversion, attention and the late positive component of event-related potentials. Biological Psychology, 20(4), 249-259. doi: 10.1016/0301-0511(85)90001-8

Deci, E., Koestner, R., \& Ryan, R. (1999). A meta-analytic review of experiments examining the effect of extrinsic rewards on intrinsic motivation. Psychological Bulletin, 125, 627-692. doi: 10.1037/0033-2909.125.6.627

DeWall, C. N., Baumeister, R. F., Mead, N. L., \& Vohs, K. D. (2011). How leaders selfregulate their task performance: evidence that power promotes diligence, depletion, and disdain. Journal of Personality and Social Psychology, 100(1), 47-65. doi: 10.1037/a0020932

Ditraglia, G. M., \& Polich, J. (1991). P300 and introverted/extraverted personality types. Psychophysiology, 28(2), 177-184. doi: 10.1111/j.1469-8986.1991.tb00410.x

Doucet, C., \& Stelmack, R. M. (2000). An event-related potential analysis of extraversion and individual differences in cognitive processing speed and response execution. Journal of Personality and Social Psychology, 78(5), 956-964. doi: 10.1037/00223514.78.5.956

Dryden, A., Allen, H. A., Henshaw, H., \& Heinrich, A. (2017). The association between cognitive performance and speech-in-noise perception for adult listeners: A systematic literature review and meta-analysis. Trends in hearing, 21, 1-21. doi: $10.1177 / 2331216517744675$

Dweck, C. (2017). From needs to goals and representations: Foundations for a unified theory of motivation, personality, and development. Psychological Review, 124(6), 689-719. doi: 10.1037/rev0000082

Elliot, A. J. (2006). The hierarchical model of approach-avoidance motivation. Motivation and Emotion, 30(2), 111-116. doi: 10.1007/s11031-006-9028-7

Enge, S., Fleischhauer, M., Brocke, B., \& Strobel, A. (2008). Neurophysiological measures of involuntary and voluntary attention allocation and dispositional differences in need for cognition. Personality \& Social Psychology Bulletin, 34(6), 862-874. doi: $10.1177 / 0146167208315556$

Eysenck, H. J. (1967). The Biological Basis of Personality. Thomas: Spring-field, III.

Eysenck, H. J. (1990). Biological dimensions of personality Handbook of Personality: Theory and research. (pp. 244-276). New York, NY, US: The Guilford Press.

Eysenck, M. W., \& Calvo, M. G. (1992). Anxiety and performance: The processing efficiency theory. Cognition and Emotion, 6(6), 409-434. doi: 10.1080/02699939208409696

Eysenck, M. W., \& Derakshan, N. (2011). New perspectives in attentional control theory. Personality and Individual Differences, 50(7), 955-960. doi: 10.1016/j.paid.2010.08.019

Eysenck, M. W., Derakshan, N., Santos, R., \& Calvo, M. G. (2007). Anxiety and cognitive performance: attentional control theory. Emotion, 7(2), 336-353. doi: 10.1037/15283542.7.2.336

Francis, A. L., Bent, T., Schumaker, J., Love, J., \& Silbert, N. (2021). Listener characteristics differentially affect self-reported and physiological measures of effort associated with 
two challenging listening conditions. Attention, Perception, \& Psychophysics. doi: 10.3758/s13414-020-02195-9

Gale, A., Bull, R., Penfold, V., Colestt, M., \& Barraclough, R. (1972). Extroversion, time of day, vigilance performance, and physiological arousal: Failure to replicate traditional findings. Psychonomic Science, 29(1), 1-5. doi: 10.3758/BF03336547

Gelman, A., \& Carlin, J. (2014). Beyond power calculations: assessing type S (sign) and type M (magnitude) errors. Perspectives on Psychological Science, 9(6), 641-651. doi: $10.1177 / 1745691614551642$

Gendolla, \& Richter, M. (2010). Effort mobilization when the self is involved: Some lessons from the cardiovascular system. Review of General Psychology, 14(3), 212-226. doi: $10.1037 / \mathrm{a} 0019742$

Gilzenrat, M. S., Nieuwenhuis, S., Jepma, M., \& Cohen, J. D. (2010). Pupil diameter tracks changes in control state predicted by the adaptive gain theory of locus coeruleus function. Cognitive, Affective \& Behavioural Neuroscience, 10(2), 252-269. doi: 10.3758/cabn.10.2.252

Gurrera, R. J., O'Donnell, B. F., Nestor, P. G., Gainski, J., \& McCarley, R. W. (2001). The P3 auditory event-related brain potential indexes major personality traits. Biological Psychiatry, 49(11), 922-929. doi: 10.1016/S0006-3223(00)01067-2

Gurrera, R. J., Salisbury, D. F., O'Donnell, B. F., Nestor, P. G., \& McCarley, R. W. (2005). Auditory P3 indexes personality traits and cognitive function in healthy men and women. Psychiatry Research, 133(2), 215-228. doi: 10.1016/j.psychres.2004.09.009

Hackley, S. A., \& Valle-Inclán, F. (1998). Automatic alerting does not speed late motoric processes in a reaction-time task. Nature, 391(6669), 786-788. doi: 10.1038/35849

Harrer, M. C., P. \& Ebert, D. (2019). Doing Meta-Analysis in R (Version 1.0.0).

Hartung, J., \& Knapp, G. (2001). A refined method for the meta-analysis of controlled clinical trials with binary outcome. Statistics in Medicine, 20(24), 3875-3889. doi: 10.1002/sim.1009

Henderlong, J., \& Lepper, M. R. (2002). The effects of praise on children's intrinsic motivation: A review and synthesis. Psychological Bulletin, 128(5), 774-795. doi: 10.1037/0033-2909.128.5.774

Herrmann, B., \& Johnsrude, I. S. (2020). A model of listening engagement (MoLE). Hearing Research, 397, 1-12. doi: 10.1016/j.heares.2020.108016

Higgins, J., Thomas, J., Chandler, J., Cumpston, M., Li, T., Page, M., \& (eds), W. V. (2019). Cochrane Handbook for Systematic Reviews of Interventions Retrieved from www.training.cochrane.org/handbook

Higgins, J. P. T., Altman, D. G., Gøtzsche, P. C., Jüni, P., Moher, D., Oxman, A. D., Savović, J., Schulz, K. F., Weeks, L., \& Sterne, J. A. C. (2011). The Cochrane Collaboration's tool for assessing risk of bias in randomised trials. Bmj, 343, d5928. doi: 10.1136/bmj.d5928

Higgins, J. P. T., \& Thompson, S. G. (2002). Quantifying heterogeneity in a meta-analysis. Statistics in Medicine, 21(11), 1539-1558. doi: 10.1002/sim.1186

Hirst, R. J., Cragg, L., \& Allen, H. A. (2018). Vision dominates audition in adults but not children: A meta-analysis of the Colavita effect. Neuroscience \& Biobehavioral Reviews, 94, 286-301. doi: 10.1016/j.neubiorev.2018.07.012

Hodgetts, W. E., Aalto, D., Ostevik, A., \& Cummine, J. (2018). Changing hearing performance and sound preference with words and expectations: Meaning responses in audiology. Ear and Hearing, 40(3), 615-620. doi: 10.1097/aud.0000000000000634

Horne, J. A., \& Pettitt, A. N. (1985). High incentive effects on vigilance performance during 72 hours of total sleep deprivation. Acta Psychol (Amst), 58(2), 123-139. doi: 10.1016/0001-6918(85)90003-4

Hornsby, B. W. Y. (2013). The Effects of Hearing Aid Use on Listening Effort and Mental Fatigue Associated With Sustained Speech Processing Demands. Ear and Hearing, 34(5), 523-534. doi: 10.1097/AUD.0b013e31828003d8

Hughes, S. E., Hutchings, H. A., Rapport, F. L., McMahon, C. M., \& Boisvert, I. (2018). Social Connectedness and Perceived Listening Effort in Adult Cochlear Implant 
Users: A Grounded Theory to Establish Content Validity for a New Patient-Reported Outcome Measure. Ear and Hearing, 39(5), 922-934. doi:

10.1097/AUD.0000000000000553

Hullett, C., \& Levine, T. (2003). The overestimation of effect sizes from F values in metaanalysis: The cause and a solution. Communication Monographs, 70, 52-67. doi: $10.1080 / 03637750302475$

IntHout, J., loannidis, J. P. A., Rovers, M. M., \& Goeman, J. J. (2016). Plea for routinely presenting prediction intervals in meta-analysis. BMJ open, 6(7), 1-6. doi: 10.1136/bmjopen-2015-010247

John, O. P., Naumann, L. P., \& Soto, C. J. (2008). Paradigm shift to the integrative big five trait taxonomy: history, measurement, and conceptual issues Handbook of Personality: Theory and Research (3rd ed., pp. 114-158). New York, NY, US: The Guilford Press.

Kahneman, D. (1973). Attention and Effort. Englewood Cliffs, NJ: Prentice-Hall, Inc.

Kahneman, D., \& Peavler, W. S. (1969). Incentive effects and pupillary changes in association learning. Journal of Experimental Psychology, 79(2), 312-318. doi: 10.1037/h0026912

Kahneman, D., Peavler, W. S., \& Onuska, L. (1968). Effects of verbalization and incentive on the pupil response to mental activity. Canadian Journal of Psychology, 22(3), 186196. doi: $10.1037 / \mathrm{h} 0082759$

Kang, G., Wang, L., \& Zhou, X. (2017). Reward interacts with modality shift to reduce crossmodal conflict. Journal of Vision, 17(1). doi: 10.1167/17.1.19

Kirby, J., \& Sonderegger, M. (2018). Mixed-effects design analysis for experimental phonetics. Journal of Phonetics, 70, 70-85. doi: 10.1016/j.wocn.2018.05.005

Kluger, A. N., \& DeNisi, A. (1996). The effects of feedback interventions on performance: A historical review, a meta-analysis, and a preliminary feedback intervention theory. Psychological Bulletin, 119(2), 254-284. doi: 10.1037/0033-2909.119.2.254

Koelewijn, T., Zekveld, A. A., Lunner, T., \& Kramer, S. E. (2018). The effect of reward on listening effort as reflected by the pupil dilation response. Hearing Research, 367, 106-112. doi: 10.1016/j.heares.2018.07.011

Krenn, B., Würth, S., \& Hergovich, A. (2013). The impact of feedback on goal setting and task performance. Swiss Journal of Psychology, 72(2), 79-89. doi: 10.1024/14210185/a000101

Kruglanski, A. W., Belanger, J. J., Chen, X., Kopetz, C., Pierro, A., \& Mannetti, L. (2012). The energetics of motivated cognition: a force-field analysis. Psychological Review, 119(1), 1-20. doi: 10.1037/a0025488

Krupski, A., Raskin, D. C., \& Bakan, P. (1971). Physiological and personality correlates of commission errors in an auditory vigilance task. Psychophysiology, 8(3), 304-311. doi: 10.1111/j.1469-8986.1971.tb00460.x

Lakens, D. (2013). Calculating and reporting effect sizes to facilitate cumulative science: a practical primer for t-tests and ANOVAs. Frontiers in psychology, 4(863), 1-12. doi: 10.3389/fpsyg.2013.00863

Larisch, R., Kotter, R., Kehren, F., Tosch, M., Shah, N. J., Kalveram, K. T., Jancke, L., \& Muller-Gartner, H. W. (1999). Motivation effects in a dichotic listening task as evident from functional magnetic resonance imaging in human subjects. Neurosci Lett, 267(1), 29-32. doi: 10.1016/s0304-3940(99)00312-2

Lenhard, W., \& Lenhard, A. (2016). Calculation of Effect Sizes. Retrieved from https://www.psychometrica.de/effect size.html

Marslen-Wilson, W., \& Tyler, L. K. (1980). The temporal structure of spoken language understanding. Cognition, 8(1), 1-71. doi: 10.1016/0010-0277(80)90015-3

Matthen, M. (2016). Effort and displeasure in people who are hard of hearing. Ear and Hearing, 37, 28S-34S. doi: 10.1097/Aud.0000000000000292

Mattys, S. L., Davis, M. H., Bradlow, A. R., \& Scott, S. K. (2012). Speech recognition in adverse conditions: A review. Language and Cognitive Processes, 27(7-8), 953-978. doi: 10.1080/01690965.2012.705006 
McAuley, J. D., Henry, M. J., Wedd, A., Pleskac, T. J., \& Cesario, J. (2012). Effects of musicality and motivational orientation on auditory category learning: A test of a regulatory-fit hypothesis. Memory \& Cognition, 40(2), 231-251. doi: 10.3758/s13421011-0146-4

McCabe, K., \& Fleeson, W. (2012). What is extraversion for? Integrating trait and motivational perspectives and identifying the purpose of extraversion. Psychological science, 23, 1498-1505. doi: 10.1177/0956797612444904

McCabe, K. O., \& Fleeson, W. (2016). Are traits useful? Explaining trait manifestations as tools in the pursuit of goals. Journal of Personality and Social Psychology, 110(2), 287-301. doi: 10.1037/a0039490

McMahon, C. M., Boisvert, I., de Lissa, P., Granger, L., Ibrahim, R., Lo, C. Y., Miles, K., \& Graham, P. L. (2016). Monitoring alpha oscillations and pupil dilation across a performance-intensity function. Frontiers in psychology, 7, 1-12. doi: ARTN 745 10.3389/fpsyg.2016.00745

Miles, K., McMahon, C., Boisvert, I., Ibrahim, R., de Lissa, P., Graham, P., \& Lyxell, B. (2017). Objective assessment of listening effort: Coregistration of pupillometry and EEG. Trends in hearing, 21, 1-13. doi: 10.1177/2331216517706396

Mirkovic, B., Debener, S., Schmidt, J., Jaeger, M., \& Neher, T. (2019). Effects of directional sound processing and listener's motivation on EEG responses to continuous noisy speech: Do normal-hearing and aided hearing-impaired listeners differ? Hearing Research, 377, 260-270. doi: 10.1016/j.heares.2019.04.005

Moher, D., Liberati, A., Tetzlaff, J., Altman, D. G., \& Group, P. (2009). Preferred reporting items for systematic reviews and meta-analyses: the PRISMA statement. PLoS medicine, 6(7), e1000097. doi: 10.1371/journal.pmed.1000097

Mumm, J., \& Mutlu, B. (2011). Designing motivational agents: The role of praise, social comparison, and embodiment in computer feedback. Computers in Human Behavior, 27(5), 1643-1650. doi: 10.1016/j.chb.2011.02.002

Murray, H. A. (1938). Explorations in Personality: A Clinical and Experimental Study of Fifty Men of College Age. Oxford, England: Oxford University Press.

Nicholls, J. G. (1984). Achievement motivation: conceptions of ability, subjective experience, task choice, and performance. Psychological Review, 91(3), 328-346. doi: 10.1037/0033-295X.91.3.328

Ortiz, T., \& Maojo, V. (1993). Comparison of the P300 wave in introverts and extraverts. Personality and Individual Differences, 15(1), 109-112. doi: 10.1016/01918869(93)90051-4

Petersen, E. B., Wöstmann, M., Obleser, J., Stenfelt, S., \& Lunner, T. (2015). Hearing loss impacts neural alpha oscillations under adverse listening conditions. Frontiers in psychology, 6, 177-177. doi: 10.3389/fpsyg.2015.00177

Petrie, C. R., \& Carrel, S. D. (1976). The relationship of motivation, listening capability, initial information, and verbal organizational ability to lecture comprehension and retention. Communication Monographs, 43(3), 187-194. doi: 10.1080/03637757609375931

Pichora-Fuller, M. K., Kramer, S. E., Eckert, M. A., Edwards, B., Hornsby, B. W., Humes, L. E., Lemke, U., Lunner, T., Matthen, M., Mackersie, C. L., Naylor, G., Phillips, N. A., Richter, M., Rudner, M., Sommers, M. S., Tremblay, K. L., \& Wingfield, A. (2016). Hearing Impairment and Cognitive Energy: The Framework for Understanding Effortful Listening (FUEL). Ear and Hearing, 37 Suppl 1, 5S-27S. doi: 10.1097/AUD.0000000000000312

Picou, E. M., \& Ricketts, T. A. (2014). Increasing motivation changes subjective reports of listening effort and choice of coping strategy. International Journal of Audiology, 53(6), 418-426. doi: 10.3109/14992027.2014.880814

Pisoni, D. B., \& Tash, J. (1974). Reaction times to comparisons within and across phonetic categories. Perception \& Psychophysics, 15(2), 285-290. doi: 10.3758/BF03213946

Plain, B., Richter, M., Zekveld, A. A., Lunner, T., Bhuiyan, T., \& Kramer, S. E. (2020). Investigating the Influences of Task Demand and Reward on Cardiac Pre-Ejection 
Period Reactivity During a Speech-in-Noise Task. Ear and Hearing, Publish Ahead of Print, 1-14. doi: 10.1097/aud.0000000000000971

Polich, J., \& Martin, S. (1992). P300, cognitive capability, and personality: A correlational study of university undergraduates. Personality and Individual Differences, 13(5), 533-543. doi: 10.1016/0191-8869(92)90194-T

Preacher, K., Rucker, D., MacCallum, R., \& Nicewander, A. (2005). Use of the extreme groups approach: A critical reexamination and new recommendations. Psychological methods, 10,178-192. doi: 10.1037/1082-989X.10.2.178

Pritchard, W. S. (1989). P300 and EPQ/STPI personality traits. Personality and Individual Differences, 10(1), 15-24. doi: 10.1016/0191-8869(89)90172-4

Putwain, D. W., Shah, J., \& Lewis, R. (2014). Performance-evaluation threat does not adversely affect verbal working memory in high test-anxious persons. Journal of Cognitive Education and Psychology(1), 120-136. doi: 10.1891/1945-8959.13.1.120

R Core Team. (2018). The R Foundation for Statistical Computing Platform. Retrieved from http://www.R-project.org

Rammsayer, T., \& Stahl, J. (2004). Extraversion-related differences in response organization: evidence from lateralized readiness potentials. Biological Psychology, 66(1), 35-49. doi: 10.1016/j.biopsycho.2003.08.003

Richter. (2016). The moderating effect of success importance on the relationship between listening demand and listening effort. Ear and Hearing, 37 Suppl 1, 111S-117S. doi: 10.1097/AUD.0000000000000295

Rohatgi, A. (2020). WebPlotDigitizer (Version 4.3). Retrieved from https://automeris.io/WebPlotDigitizer

Rönnberg, J., Holmer, E., \& Rudner, M. (2019). Cognitive hearing science and ease of language understanding. International Journal of Audiology, 58(5), 247-261. doi: 10.1080/14992027.2018.1551631

Rosenthal, R. (1991). Meta-Analytic Procedures for Social Research. Thousand Oaks, CA, US: Sage Publications, Inc.

Rung, J. M., \& Madden, G. J. (2018). Experimental reductions of delay discounting and impulsive choice: A systematic review and meta-analysis. Journal of Experimental Psychology; General, 147(9), 1349-1381. doi: 10.1037/xge0000462

Sarampalis, A., Kalluri, S., Edwards, B., \& Hafter, E. (2009). Objective measures of listening effort: effects of background noise and noise reduction. Journal of Speech, Language, and Hearing Research, 52(5), 1230-1240. doi: 10.1044/10924388(2009/08-0111)

Schmidt, A., Beauducel, A., Brocke, B., \& Strobel, A. (2004). Vigilance performance and extraversion reconsidered: some performance differences can indeed be induced. Personality and Individual Differences, 36(6), 1343-1351. doi: 10.1016/S01918869(03)00221-6

Schwarzer, G. (2007). Meta: An R Package for Meta-Analysis. 7, 40-45.

Sewell, E. H. (1985). Effects of orienting instructions, monetary incentives, and sex of listeners on listening comprehension. Perceptual and Motor Skills, 60(2), 511-514. doi: 10.2466/pms.1985.60.2.511

Sidik, K., \& Jonkman, J. N. (2003). On constructing confidence intervals for a standardized mean difference in meta-analysis. Communications in Statistics - Simulation and Computation, 32(4), 1191-1203. doi: 10.1081/SAC-120023885

Smillie, L., Yeo, G., Furnham, A., \& Jackson, C. (2006). Benefits of all work and no play: The relationship between neuroticism and performance as a function of resource allocation. The Journal of applied psychology, 91, 139-155. doi: 10.1037/00219010.91.1.139

Snyder, F. W., \& Snyder, C. W. (1956). The effects of monetary reward and punishment on auditory perception. The Journal of Psychology, 41(1), 177-184. doi: $10.1080 / 00223980.1956 .9916214$ 
Stanners, R. F., Coulter, M., Sweet, A. W., \& Murphy, P. (1979). The pupillary response as an indicator of arousal and cognition. Motivation and Emotion, 3(4), 319-340. doi: 10.1007/BF00994048

Strand, J. F., Brown, V. A., \& Barbour, D. L. (2020). Talking points: A modulating circle increases listening effort without improving speech recognition in young adults. Psychonomic Bulletin \& Review, 27(3), 536-543. doi: 10.3758/s13423-020-01713-y

Strand, J. F., Brown, V. A., Merchant, M. B., Brown, H. E., \& Smith, J. (2018). Measuring listening effort: Convergent validity, sensitivity, and links with cognitive and personality measures. Journal of Speech Language and Hearing Research, 61(6), 1463-1486. doi: 10.1044/2018_Jslhr-H-17-0257

Strauss, D. J., \& Francis, A. L. (2017). Toward a taxonomic model of attention in effortful listening. Cognitive Affective \& Behavioral Neuroscience, 17(4), 809-825. doi: 10.3758/s13415-017-0513-0

Suurmond, R., van Rhee, H., \& Hak, T. (2017). Introduction, comparison and validation of Meta-Essentials: A free and simple tool for meta-analysis. Research Synthesis Methods, 8(4), 537 - 553. doi: doi.org/10.1002/jrsm.1260

Thompson, S. G., \& Higgins, J. P. T. (2002). How should meta-regression analyses be undertaken and interpreted? Statistics in Medicine, 21(11), 1559-1573. doi: $10.1002 / \operatorname{sim} .1187$

Tune, G. S. (1966). Errors of commission as a function of age and temperament in a type of vigilance task. Quarterly Journal of Experimental Psychology, 18(4), 358-361. doi: $10.1080 / 14640746608400054$

Tune, S., Wostmann, M., \& Obleser, J. (2018). Probing the limits of alpha power lateralisation as a neural marker of selective attention in middle-aged and older listeners. European Journal of Neuroscience, 48(7), 2537-2550. doi: 10.1111/ejn.13862

van Doorn, R. R. A., \& Lang, J. W. B. (2010). Performance differences explained by the neuroticism facets withdrawal and volatility, variations in task demand, and effort allocation. Journal of Research in Personality, 44(4), 446-452. doi: 10.1016/j.jrp.2010.05.004

Wallace, J. F., \& Newman, J. P. (1997). Neuroticism and the attentional mediation of dysregulatory psychopathology. Cognitive Therapy and Research, 21(2), 135-156. doi: $10.1023 / A: 1021828628571$

Wallace, J. F., \& Newman, J. P. (1998). Neuroticism and the facilitation of the automatic orienting of attention. Personality and Individual Differences, 24(2), 253-266. doi: 10.1016/S0191-8869(97)00153-0

Weis, T., Puschmann, S., Brechmann, A., \& Thiel, C. M. (2013). Positive and negative reinforcement activate human auditory cortex. Frontiers in Human Neuroscience, 7 , 842-842. doi: 10.3389/fnhum.2013.00842

Zekveld, A. A., Koelewijn, T., \& Kramer, S. E. (2018). The pupil dilation response to auditory stimuli: Current state of knowledge. Trends in hearing, 22, 1 - 25. doi: $10.1177 / 2331216518777174$

Zekveld, A. A., van Scheepen, J. A. M., Versfeld, N. J., Veerman, E. C. I., \& Kramer, S. E. (2019). Please try harder! The influence of hearing status and evaluative feedback during listening on the pupil dilation response, saliva-cortisol and saliva alphaamylase levels. Hear Res, 381, 107768. doi: 10.1016/j.heares.2019.07.005

Zhang, M. (2017). Listening Effort Allocation: Stimulus-Driven, Goal-Driven, or Both? (Doctoral dissertation, University of Pittsburgh, Pittsburgh, USA). Retrieved from http://d-scholarship.pitt.edu/32459/

Zhang, M., Siegle, G. J., McNeil, M. R., Pratt, S. R., \& Palmer, C. (2019). The role of reward and task demand in value-based strategic allocation of auditory comprehension effort. Hearing Research, 381, 1-15. doi: 10.1016/j.heares.2019.107775 


\section{Tables and figures}

Table 1. PICOS screening inclusion and exclusion criteria for the literature search

\begin{tabular}{|c|c|c|}
\hline & Inclusion criteria & Exclusion criteria \\
\hline Population & $\begin{array}{l}\text { (i) Age: } 18+\text { or description as adults. } \\
\text { (ii) Hearing: normal (either self-described or } \\
\text { measured using pure-tone audiometry to } \\
\text { appropriate British Society of Audiology standards) } \\
\text { or hearing loss (with or without the use of hearing } \\
\text { aids). }\end{array}$ & $\begin{array}{l}\text { (i) Visual impairment } \\
\text { (ii) Cognitive impairment } \\
\text { (iii) Neurological or psychiatric } \\
\text { disorders. }\end{array}$ \\
\hline Intervention & $\begin{array}{l}\text { i) Independent variable that manipulated the } \\
\text { participant's motivation to invest LE and/or increase } \\
\text { their listening task performance level. This could } \\
\text { include tangible rewards, feedback, evaluative } \\
\text { threat or perceived competence enhancing } \\
\text { interventions. } \\
\text { ii) Personality trait with relevance to effort measured } \\
\text { using a validated questionnaire (e.g. extraversion } \\
\text { measured using the Eysenck Personality } \\
\text { Questionnaire). }\end{array}$ & $\begin{array}{l}\text { Studies examining } \\
\text { (i) emotional valence e.g. } \\
\text { stimuli that elicit strong } \\
\text { emotions } \\
\text { (ii) mood or emotional state. }\end{array}$ \\
\hline Comparator & $\begin{array}{l}\text { i) Comparisons between motivated/demotivated } \\
\text { group and a control group. Comparisons between a } \\
\text { strong versus weak manipulation of motivation (e.g. } \\
\text { high versus low levels of performance-based } \\
\text { financial reward) or between a motivated and } \\
\text { unmotivated condition (e.g. a condition in which a } \\
\text { performance-based reward is offered versus } \\
\text { passive listening) } \\
\text { ii) Comparison between groups based on } \\
\text { personality traits (e.g. comparison between } \\
\text { introverts and extraverts). Correlations between } \\
\text { questionnaire scores and LE outcomes. }\end{array}$ & \\
\hline Outcome & $\begin{array}{l}\text { Self-rated, behavioural or physiological measures of } \\
\text { LE. }\end{array}$ & $\begin{array}{l}\text { Subjective outcomes not } \\
\text { directly related to LE (e.g. } \\
\text { quality of life ratings). Ratings } \\
\text { of tiredness/fatigue were } \\
\text { excluded. }\end{array}$ \\
\hline $\begin{array}{l}\text { Study } \\
\text { design }\end{array}$ & $\begin{array}{l}\text { All study designs published in English in peer- } \\
\text { reviewed or non-peer-reviewed journals, including } \\
\text { original research data; conference } \\
\text { papers/proceedings containing research data; book } \\
\text { chapters; dissertations; and theses. Grey literature } \\
\text { will also be included. The study may have been } \\
\text { published at any date. }\end{array}$ & $\begin{array}{l}\text { Exclusion criteria: Research not } \\
\text { published in English. Case } \\
\text { reports, systematic reviews will } \\
\text { not be included in the analysis } \\
\text { but may be used to source } \\
\text { research. Interviews and } \\
\text { clinical protocols will not be } \\
\text { included. }\end{array}$ \\
\hline
\end{tabular}


Table 2: Summary of included studies. This summary includes sample size, demographic information (age, hearing status) where available, details of the stimuli used, motivation manipulation/personality trait considered, listening/task demand manipulations and main findings for each LE outcome. Effect sizes (Cohen's $d$ ) and 95\% confidence intervals are included for results included in the meta-analysis.

\begin{tabular}{|c|c|c|c|c|c|c|c|c|}
\hline Author(s) & $\begin{array}{l}\text { Sample } \\
\text { Size }\end{array}$ & $\begin{array}{c}\text { Age } \\
\text { Mean (SD) } \\
\text { unless stated }\end{array}$ & $\begin{array}{l}\text { Hearing } \\
\text { level }\end{array}$ & Stimuli & $\begin{array}{c}\text { Listening / task } \\
\text { demand manipulation }\end{array}$ & $\begin{array}{c}\text { Motivation/ } \\
\text { personality variable }\end{array}$ & $\begin{array}{l}\text { Outcome } \\
\text { measure(s) }\end{array}$ & Finding(s) \\
\hline $\begin{array}{l}\text { Asbjörnsen } \\
\text { et al. (1992) }\end{array}$ & 36 & $\begin{array}{c}\text { Range: } 20- \\
30 \text { years }\end{array}$ & $\mathrm{NH}$ & Syllables & None & $\begin{array}{l}\text { Reward group - high } \\
\text { incentive } \$ 17 \text { and low } \\
\text { incentive } \$ 1.70 \text {. }\end{array}$ & $\begin{array}{l}\text { 1. Left ear } \% \\
\text { correct }\end{array}$ & $\begin{array}{l}\text { 1. For high incentive } \\
\text { group, NS increase in } \\
\text { left ear \% correct } \\
\text { when comparing } \\
\text { neutral with positive } d \\
=-0.10[-0.560 .37] \text {. } \\
\text { For the low incentive } \\
\text { group, NS changes in } \\
\% \text { correct when } \\
\text { comparing neutral with } \\
\text { positive } d=-0.19[- \\
0.65,0.26] .\end{array}$ \\
\hline $\begin{array}{l}\text { Bakan } \\
(1959)\end{array}$ & 40 & $?$ & $?$ & Digits & $\begin{array}{l}\text { Single-task and dual- } \\
\text { task conditions }\end{array}$ & $\begin{array}{l}\text { Extraversion/introversion } \\
\text { and neuroticism } \\
\text { (Covariate). }\end{array}$ & $\begin{array}{l}\text { 1. Improvement } \\
\text { in performance } \\
\text { (single } \\
\text { compared to } \\
\text { dual-task } \\
\text { condition) }\end{array}$ & $\begin{array}{l}\text { 1. Sig improvement in } \\
\text { performance for } \\
\text { extraverts } d=0.66 \\
{[0.02,1.3] \text {. }} \\
\text { NS for neuroticism } \\
\text { (effect size not } \\
\text { reported). }\end{array}$ \\
\hline $\begin{array}{l}\text { Beatty et al. } \\
\text { (1980) }\end{array}$ & 180 & $?$ & $?$ & $\begin{array}{l}\text { Lecture } \\
\text { about } \\
\text { computer } \\
\text { music }\end{array}$ & $\begin{array}{c}\text { Time compression } \\
\text { (original } 140 \text { wpm, } \\
210 \text { wpm and } 280 \\
\text { wpm) }\end{array}$ & $\begin{array}{l}\text { Course credit (amount } \\
\text { based upon performance } \\
\text { level) for three incentive } \\
\text { groups, no incentive for } \\
\text { three control groups. }\end{array}$ & $\begin{array}{c}\text { 1.Comprehensio } \\
\mathrm{n} \text { test }-20 \\
\text { items, multiple } \\
\text { choice }\end{array}$ & $\begin{array}{l}\text { 1. Sig greater } \\
\text { comprehension in the } \\
\text { incentive group. NS } \\
\text { motivation/demand } \\
\text { interaction. }\end{array}$ \\
\hline
\end{tabular}


1. Performance (hits)

2. N1 amplitude

3. P3 amplitude

$$
\text { (EPQ), }
$$

(Extreme group). 


\begin{tabular}{|c|c|c|c|}
\hline $\begin{array}{l}\text { Carolan et } \\
\text { al. }(2021)\end{array}$ & 24 & $\begin{array}{l}\text { Median } 23 \\
\text { (range } 19 \text { - } \\
\text { 33) }\end{array}$ & $\mathrm{NH}$ \\
\hline
\end{tabular}

\section{Carrillo-de- \\ la-Pena and \\ Cadaveira}

(2000)
Vocoded cue sentence hard (2 band) or intermediate (3 band). Vocoded target sentence always 3 band.
Reward. £2.50 (high) or $£ 0.25$ (low) for scoring $60 \%$ or more correct in each block.
1. Performance
(accuracy)
2. RTs

3. SR work

4. SR likelihood

of giving up
Evaluation 
$[0.26,1.12]$.

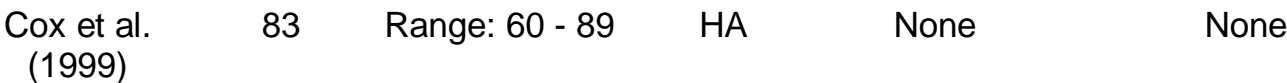
(1999)

Daruna et al. (1985)

MBTI ExtroversionIntroversion dimension Locus of Control

(Covariate).

$$
\text { (Covariate). }
$$




\section{(Experiment}

2)

\section{DeWall et al. (2011) \\ (Experiment}

4)

\section{Ditraglia and \\ Polich}

(1991)

Enge et al. (2008)

(Study 1)
NFCog,

(Extreme group).

Power manipulation as above (Exp. 1A). One group were depleted,

'suitable' or 'unsuitable' task for someone with power.

Extraversion/introversion. (EPQ and MBTI)

(Extreme group).

1. P3 amplitude

Performance

s. Performance

1. Early $\mathrm{P} 3 \mathrm{a}$

2. Late P3a
3. P3b then performed either a

than low power group $d=1.06[0.57,1.55]$ and controls $d=1.53$ $[1.03,2.03]$ in the selfcontrol depletion condition.

1. Main effect of power: high power, depleted group

performed worse than other groups $d=0.38$ $[0.07,0.69]$.

1. Sig personality*trial block interaction

showing P3 habituated in extraverts but remained consistent in introverts $d=1.25$ $[0.49,2.01]$

1. NS group differences in early P3a $d=-0.04[-0.73$ $0.65]$.

2. High NFCog showed larger late P3a amplitude compared to low NFCog $d=0.75$ [0.03, 1.47].

3. NS group differences in P3b $d=$ 0.05 [-0.64, 0.74].

\section{Enge et al.}

22 (4.3)

$\mathrm{NH}$ 
(2008)

(Study 2)

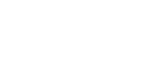

\begin{tabular}{|c|c|c|c|c|c|}
\hline $\begin{array}{l}\text { Francis et al. } \\
\quad(2021)\end{array}$ & 35 & $37.14(18-71)$ & $\mathrm{NH}$ & $\begin{array}{l}\text { Spoken } \\
\text { stories }\end{array}$ & $\begin{array}{l}\text { Speech spoken by } \\
\text { native English } \\
\text { speaker masked b } \\
\text { speech-shaped } \\
\text { noise, non-native } \\
\text { accented English } \\
\text { speech }\end{array}$ \\
\hline
\end{tabular}

Gale et al.

160

(1972)
Inventory; Sensation

Seeking Scale;

Tridimensional

Personality Questionnaire

(Extreme group,

controlled for adjacent

components).
2. Late $P 3 a$
3. $P 3 b$ 


\section{Gilzenrat et \\ al. (2010)}

(Experiment

2)

\section{Gilzenrat et \\ al. (2010) \\ (Experiment}

3)
Gurrera et
al. (2001)

Tones

If correct, the discrimination task was made more difficult. If incorrect, the difficulty level remained constant.

discriminations

High conflict

condition - $50 \%$ impossible

discriminations$$
\text { remained constant. }
$$

Reward value changed depending upon difficulty level.

Participants were able to reset the task. An 'escape trial' was defined as the resetting.

always received on

impossible trials,
depending on feedback condition).
1. RTs

2. BPD

\section{(calculated by}

multiplying the

potential reward

value of the trial

by the expected

accuracy based

on previous

performance) as

a predictor of

BPD

None

Personality - NEO Five

1. P3 amplitude trial immediately before

1. NS trend towards longer RTs in the negative cf. positive

feedback conditions $d$ $=0.36[-0.05,0.77]$.

2. NS effect on BPD $d$ $=0.17[-0.23,0.57]$

3. NS effect on PPD $d$ $=0.2[-0.2,0.6]$.

1. Sig inverted Ushape trend for BPD

(quadratic trend

analysis) $d=1.03$

$[0.59,1.47]$

2. Expected value showed a sig

quadratic trend

centred on the escape trial, similar to BPD $d$ $=1.47[0.96,1.98]$. Factor (all sites)
Effect sizes when all sites are combined (significance unknown): negative correlation with neuroticism $d=0.31$ $[-0.25,0.87]$, positive correlation with 


\section{Gurrera et \\ al. (2005)}

$?$
$?$
Digits
None
None

\section{Primed to expect an easy} or hard task.

\section{Rewards for hits, fines for misses, with increasing value over 3 days (one group sleep deprived).}

None

High financial reward (5

extraversion $d=0.75$ [0.16, 1.34], openness $d=0.77$ [0.17, 1.37], agreeableness $d=$ $0.93[0.33,1.53]$ and conscientiousness $d=$ $0.65[0.05,1.25]$.

Personality- NEO FiveFactor Inventory (NEO

(Covariate).
1. P3 amplitude (all sites)

1. Effect sizes when all sites are combined (significance

unknown): Negative correlation with neuroticism $d=0.57$ [0.18, 0.96], positive correlation with extraversion $d=0.47$ $[0.08,0.86]$, openness $\mathrm{d}=0.04$ [-0.38, 0.46], agreeableness $d=$ $0.82[0.44,1.2]$ and conscientiousness $d=$ $0.26[-0.14,0.66]$.

1. Participants in the "hard prime" group performed sig better (lower SNR) than those in the "easy prime" group $d=0.5$ [$0.02,1.02]$.

1. $d$

1. Sig greater $d$ for sleep-deprived incentive versus no incentive $d=1.03$ [$0.29,2.35]$.
1. Sig more high 
and Peavler

(1969)

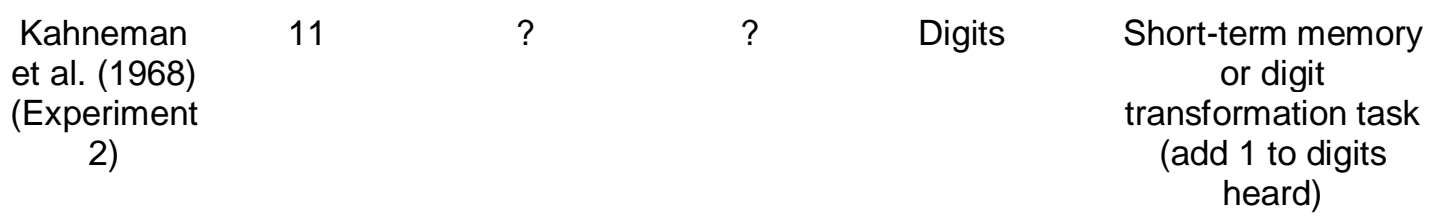

Kang et al. (2017)

(Experiment

1) cents) for recall of nouns paired with odd digits, low reward (1 cent) for recall of each noun paired with even digit.
2. MPD: a. following digit presentation

b. following response noun
Low (2 cents) or high (10 cents) reward for correct trials.

heard

Auditory letter was paired with either a congruent or

incongruent visual letter
1. RTs for correct

responses

2. Error rates
Financial reward - reward maximum of 12 yuan) or no reward conditions for fast and accurate responses. (1 yuan per trial up to a
1. Performance PPD between listening and response period reward items correctly recalled than low $d=$

$$
1.5[0.6,2.4]
$$

2a. NS effects on MPD.

2b. Sig larger MPD following high reward nouns $d=1.00[0.24$,

$$
\text { 1.76]. }
$$

1. NS effects on performance.

2. Sig task*incentive interaction - incentive had a sig effect on PPD in the short-term memory task $d=0.91$ $[0.21,1.61]$.but not the digit transformation task (effect size not reported)

1. Smaller interference effect on RT in the reward condition compared to no reward for auditory targets $d=0.56[0.11$, 1.01].

2. NS effect of reward on error rates for congruent targets $d=-$ 0.05 [-0.47, 0.37] or for incongruent targets $d=0.13$ [-0.29, 0.55].
1. NS main effect of reward on SRT $d=$ 0.04 [-0.6, 0.52] 
procedure to track

85\% (easy) and 50\%

(hard) target

intelligibility levels.

\section{Krupski et al. \\ (1971)}

Larisch et al.

(1999)
5

\author{
Range: 20 -
}

28
31

Range: 18 -
21
Range: 20 -
28

$\mathrm{NH}$

Syllables

None

Single-task or dual-

task conditions

Extraversion/introversion and neuroticism (Covariate).

Participants informed that the task indexed

intelligence and could differentiate successful and unsuccessful people.

Highest score would receive $\sim \$ 200$ under high vs. c. BPD

3a. SR effort

b. SR quitting
1.

Commissioning
errors

2a. NS main effect of reward on MPD $d=$

0.44 [-0.03, 0.91].

$2 \mathrm{~b}$ Sig effect of reward on PPD $d=0.46[-$

$0.01,0.92]$.

2c. NS main effect of reward on BPD $d=$

$0.04[-0.4,0.48]$

3a NS effect of reward

on SR effort $d=0.03$

$[-0.53,0.59]$.

3b. NS effect of

reward on SR quitting

$d=0.2[-0.32,0.72]$.

1. Sig correlation between

commissioning errors and extraversion $d=$

0.7 [0.24, 1.16], NS for neuroticism $d=0.24$ [$0.23,0.71]$.

1. fMRI contrasts assessing differential voxel activations neutral

motivation

2. Performance
1. No effect seen in 2 participants, but 3 participants showed increased BOLD response in right $B A$ 35 and in posterior cingulate (BA 23).

Decreased BOLD response seen in right BA 46.

2. NS trend towards better performance under high compared to neutral motivation $d$ $=0.2[-0.69,1.09]$. 


\section{McAuley et \\ al. (2012) \\ (Experiment}

1)

\section{McAuley et \\ al. (2012)}

(Experiment

2)
$?$

Tones

None

Omnidirectional (low SNR) or directional (high SNR) microphone hearing aid simulator
}

Self-identified musicians were primed with a positive stereotype.

Gains condition (awarded points for correct answers), losses condition (deducted points for incorrect answers).

Participants primed for promotion or prevention focus.
1. Improvement in performance across 8 trials

Sig improvement for musicians compared to non-musicians in the gains condition $d=$ $0.65[0.07,1.23]$. In the loss condition. improvement for nonmusicians was NS better than for musicians $d=0.07$ $0.5,0.64]$.

1. \% correct

1. Promotion-focus participants performed sig better in the gain condition compared to the losses condition $d$ $=1.16[0.6,1.72]$. Prevention-focus participants did not perform sig better in the losses condition compared to the gain condition $d=0.22$ [$0.3,0.74]$.

$€ 20$ reward offered in one of the two sessions.

1. \% correct on comprehension task 2. EEG impulse responses
1. Sig effect of reward on \% correct at low SNR (both groups) $d=$ 0.76 [0.45, 1.07].

Sig main effect on \% correct for $\mathrm{HI} d=0.78$ $[0.37,1.19]$.

NS main effect on \% correct for $\mathrm{NH} d=$ $0.44[-0.13,1.01]$.

2. NS effect of reward on EEG impulse 


\begin{tabular}{|c|c|c|c|c|c|c|c|c|}
\hline $\begin{array}{c}\text { Ortiz and } \\
\text { Maojo } \\
\text { (1993) }\end{array}$ & 20 & $\begin{array}{l}19 \text { (both } \\
\text { groups) }\end{array}$ & $?$ & Tones & None & $\begin{array}{l}\text { Extraversion (EPI) } \\
\text { (Extreme group). }\end{array}$ & $\begin{array}{l}\text { 1. P3 amplitude } \\
\text { 2. P3 latency }\end{array}$ & $\begin{array}{c}\text { 1. Sig greater P3 } \\
\text { amplitude in introverts } \\
d=2.61[1.74,3.48] . \\
2 . \text { NS difference in P3 } \\
\text { latency between } \\
\text { groups } d=0.47[-0.17, \\
1.11] .\end{array}$ \\
\hline $\begin{array}{c}\text { Petrie and } \\
\text { Carrel } \\
(1976)\end{array}$ & 100 & $?$ & $?$ & $\begin{array}{l}\text { 20-minute } \\
\text { lecture on TV } \\
\text { and radio } \\
\text { speaking }\end{array}$ & None & $\begin{array}{l}\text { Participants informed } \\
\text { they were chosen for } \\
\text { special training based on } \\
\text { their qualifications. }\end{array}$ & $\begin{array}{l}\text { 1. Performance } \\
\text { on multiple } \\
\text { choice } \\
\text { comprehension } \\
\text { test }\end{array}$ & $\begin{array}{c}1 . \text { Sig higher } \\
\text { comprehension scores } \\
\text { in the motivated group } \\
d=0.51[0.11,0.91] .\end{array}$ \\
\hline $\begin{array}{l}\text { Picou and } \\
\text { Ricketts } \\
(2014) \\
\text { (Experiment } \\
1)\end{array}$ & 16 & 24.87 & $\mathrm{NH}$ & $\begin{array}{l}\text { Sentences } \\
\text { (audio only) }\end{array}$ & $\begin{array}{l}\text { Background cafeteria } \\
\text { noise presented at } \\
\text { easy and hard SNRs } \\
\text { (corresponding to } \\
\text { approx. } 50 \% \text { and } \\
80 \% \text { correct in pilot } \\
\text { testing) }\end{array}$ & $\begin{array}{l}\text { Participants informed of } \\
\text { an upcoming } \\
\text { comprehension test } \\
\text { (motivated) or were not } \\
\text { tested (unmotivated). }\end{array}$ & $\begin{array}{l}\text { 1a. SR effort } \\
\text { 1b. SR } \\
\text { avoidance } \\
\text { 1c. SR control }\end{array}$ & $\begin{array}{c}\text { 1a. Sig effect on SR } \\
\text { effort for hard SNR } d= \\
0.6[0.11,1.09] . \\
\text { 1b. NS effect on SR } \\
\text { avoidance for hard } \\
\text { SNR } d=0.28[-0.34, \\
0.9] \text {. } \\
\text { 1c. NS effect on SR } \\
\text { control for hard SNR } d \\
=0.26[-0.36,0.88] .\end{array}$ \\
\hline $\begin{array}{l}\text { Picou and } \\
\text { Ricketts } \\
\text { (2014) } \\
\text { (Experiment } \\
\text { 2) }\end{array}$ & 16 & 23.44 & $\mathrm{NH}$ & $\begin{array}{c}\text { Sentences } \\
\text { (audio plus } \\
\text { visuals) }\end{array}$ & $\begin{array}{c}\text { Background cafeteria } \\
\text { noise presented at } \\
\text { two SNRs (hard SNR } \\
50 \% \text { and easy SNR } \\
80 \% \text { ) }\end{array}$ & $\begin{array}{l}\text { Participants informed of } \\
\text { an upcoming } \\
\text { comprehension test } \\
\text { (motivated) or were not } \\
\text { tested (unmotivated). }\end{array}$ & $\begin{array}{l}\text { 1a. SR effort } \\
\text { 1b. SR } \\
\text { avoidance } \\
\text { 1c. SR control }\end{array}$ & $\begin{array}{c}\text { 1a. Sig effect on SR } \\
\text { effort for hard SNR } d= \\
0.68 \text { [0.19, } 1.17] \text {. } \\
\text { 1b. NS effect on SR } \\
\text { avoidance for hard } \\
\text { SNR } d=0.42[-0.14 \\
0.98] . \\
\text { 1c. Sig effect on SR } \\
\text { control for hard SNR } d \\
=0.53[-0.01,1.07] .\end{array}$ \\
\hline Plain et al. & 32 & $22.22(3.03)$ & $\mathrm{NH}$ & Sentences & Six SNRs & High $(€ 5)$ or low $(€ 0.20)$ & 1. Performance & 1. NS reward*SNR \\
\hline
\end{tabular}




\section{Polich and}

Martin

(1992)
54

$19.4(1.1)$

$?$

Tones

Target stimulus

probability either .20 ,

.50 or .80 reward for scoring $>70 \%$ correct in each block.
2. PEP

3. SR effort

4. SR quitting interaction for performance $d=0.16$

$[-0.32,0.64]$

2. NS reward* ${ }^{*} N R$ interaction for PEP $d=$ $0.15[-0.33,0.63]$.

3. NS reward*SNR

interaction for SR effort $d=0.07[-0.41$ $0.55]$.

4. NS reward*SNR interaction for SR

quitting $d=0.14$ [$0.34,0.62]$.

Extraversion/introversion, 1. P3 amplitude sensing/seeing, thinking/feeling judgment/perception (MBTI), extraversion, neuroticism

psychoticism, Lie (EPQ) (Covariate).
2. P3 latency

1. For the whole group, NS correlations between and $P 3$ amplitude and personality variables (extraversion/introvers ion $d=-0.02[-0.4$,

0.36 ]; sensing/intuiting $d=0.24[-0.12,0.6]$ thinking/feeling $d=$ 0.54 [0.19, 0.89];

judgement/perception $d=0.18[-0.18,0.54]$; extraversion $d=0.06$ $[-0.31,0.43]$

neuroticism $d=0.47$ $[0.12,0.82]$;

psychoticism $d=0.45$ $[0.1,0.8]$; Lie $d=-0.35$ $[-0.77,0.07])$.

2. For the whole group, NS correlations between P3 latency and personality 
(extraversion/introvers

ion $d=-0.26[-0.62$

$0.1]$; sensing/intuiting

$d=-0.02[-0.4,0.36]$;

thinking/feeling $d=-$

0.14 [-0.53, 0.25];

judgement/perception

$d=0.26[-0.1,0.62]$

extraversion $\mathrm{d}=0.02$

$[-0.36,0.4]$;

neuroticism $d=-0.45$

[-0.89, -0.01];

psychoticism $d=0.04$

$[-0.33,0.41]$; Lie $d=$

$0.49[0.14,0.84])$.

Pritchard

(1989)

37

Male 23.8

Range: 19.17

$-30.25)$

Female 24.4

(Range: 18.75

- 30.92)

Rammsayer

and Stahl

(2004)

$25.7( \pm 5.7$
years $)$

$?$

years)
None

ones

PQ (all scales)

(Covariate).

Personality - EPQ
(extraversion)

(Extreme group).
1. P3 amplitude

2. P3 latency

1. For males, sig correlation between

Lie scale and P3 amplitude.

2. For males, sig

inverse correlation between P3 latency and neuroticism.

1. Response

errors
2. RT

3. N1 latencies

4. N1 amplitude

5. P3 latency

6. P3 amplitude

7. S-LRP

latency

\section{NS differences in} response errors

between introverts and extraverts $d=0.2$ [-0.54, 0.94].

2. NS differences in RT $d=0.17$ [-0.57, $0.91]$.

3. NS differences in $\mathrm{N} 1$ latency $d=0.08$ [$0.66,0.82]$.

4. Sig larger N1 amplitude for 
introverts $d=0.92$

5. Sig slower P3

latency for extraverts $d=0.88[0.1,1.66]$.

6. NS group

differences in $\mathrm{P} 3$ amplitude $d=0.47$ [-

$0.28,1.22]$

7. NS group

differences om S-LRP latency $d=0.24[-0.5$, 0.98 .

\section{Richter}

(2016)

23.88

16

Tones

Sine waves presented in pairs differing by $20 \mathrm{~Hz}$ (easy condition) or 3 $\mathrm{Hz}$ (hard condition)
$\$ 0.20$ (low) or $\$ 2$ (high) reward for scoring $>90 \%$ correct in each block of 25 trials.
1. Cardiac reactivity:

1a. PEP

1b. HR

1c. SBP

1d. DBP

2. RT

3. \% correct

\section{Schmidt et $\quad 74$ (36}

al. (2004)
Personality extraversion/introversion
1. RT to targets

2. Hits 1a. Sig effect of reward on PEP for hard condition $d=$ 2.97 [2.12, 3.82]. 1b. Sig effect of reward on HR for hard condition $d=1.00$ [0.37, 1.63].

1c. NS effect of reward on SBP for hard condition $d=$ $0.39[-0.24,1.02]$. $1 d$. NS effect of reward on DBP for hard condition $d=$ $0.18[-0.43,0.79]$.

2. NS effect of reward on RT $d=0.17[-0.45$, 0.79 ].

3. NS effect of reward on \% correct $d=0.30$ $[-0.20,0.80]$

1. NS main effect on RT $d=0.08[-0.38$, 
s and

38

Extrave

rts)

\section{Sewell}

(1985)

\section{0}

19.7

Lecture
(subject
unknown)

\section{Snyder and Snyder}

(1956)

\section{Stanners et}

al. (1979)

(Experiment

2)

unknown)

Audiobook

$41 \quad 19.8$

$?$

Andiobok

$?$

Undergraduate

$\mathrm{S}$
(Extreme group).

None
Digits
Digit transformation - add either 0,1 or 3 to each digit
Financial reward (5 cents

$$
\text { per trial). }
$$

Orientating instructions: either 'interesting',

'boring' or no orientation; Financial reward (up to $\$ 2.50$ based on performance).

Participants rewarded for recall from the target speaker only (but were unaware of this). 
(easy)/67 dB (hard)

depending upon

condition) semantic dual

$$
\text { task) }
$$

3. Recall: CSCT

(updating/inhibiti

ng) in high load

and low load

conditions

4. PPD
$=0.56$ [0.32, 0.8].

2. NS associations

between extraversion

and complex dual task

RT $d=-0.1[-0.37$,

$0.17]$ and semantic

dual task RT $d=0.1$ [

$0.16,0.36]$, HSPS and complex dual task RT

$d=0.75[0.51,0.99]$

and semantic dual

task RT $d=0.63$

[0.39, 0.87].

3. NS associations

between extraversion and CSCT (updating) $d=0.04$ [-0.22, 0.3]

CSCT (inhibiting) $d=$

0.02 [-0.24, 0.28];

CSCT (low load) $d=$

0.32 [0.07, 0.57];

CSCT (high load) $d=$

$0.1[-0.37,0.17]$. NS

associations between

HSPS and CSCT

(updating) $d=-0.24[-$

$0.52,0.04]$, CSCT

(inhibiting) $d=-0.16$ [-

$0.44,0.12]$, CSCT

(low load) $d=-0.3[-$

0.59, -0.01], CSCT

(high load) $d=-0.14$ [-

$0.41,0.13]$.

4. NS associations

between PPD and

extraversion $d=-0.2$ [-

$0.48,0.08]$ and HSPS

$d=0.08$ [-0.18, 0.34]. 
Tune (1966)

$$
\begin{gathered}
\text { Old (Introverts } \\
65.9, \\
\text { Extraverts } \\
65.3 \text { ) and } \\
\text { young } \\
\text { (Introverts }
\end{gathered}
$$

35.5,

\section{Extraverts}

38.1)

Tune et al.

(2018)
29

56 (median)

$\mathrm{NH} / \mathrm{HI}$

Digits
Extraversion/introversion (Heron inventory)

(Extreme group - median split) between Heron score and $d$ on the task

1. Correlation

Agreeableness,

conscientiousness

extraversion, neuroticism,

openness (Big five)

(Covariate)

\section{Correlations \\ between}

personality

subdomains and

1. Performance

$$
\text { 2. EEG }
$$

parameters:

2a. AMI alpha

2b. Amplitude

ALI $0.8 \mathrm{~Hz}$

2c. Amplitude

ITPC $0.8 \mathrm{~Hz}$

2d. ITPC
1. NS positive

Spearman's

correlation between

extraversion score

and $d ; d=0.53[0.13$,

$$
0.93] \text {. }
$$

1. Performance:

Agreeableness $d=$

$0.28[-0.54,1.12]$

$$
\text { (NS), }
$$

openness $d=-0.14$ [$0.98,0.68]$ (NS),

extraversion $d=0.37$

$[-0.43,1.25]$ (NS),

neuroticism $d=0.65$

$[-0.16,1.58]$ (NS),

conscientiousness $d=$

$0.28[-0.52,1.54]$

(NS).

2a. AMI alpha:

Agreeableness $d=$

$0.56[-0.26,1.46]$ (NS),

openness $d=0.22$ [-

$0.58,1.07]$ (NS)

extraversion $d=0.20$

$[-0.61,1.04]$ (NS),

neuroticism $d=0.06$

$[-0.77,0.90]$ (NS),

conscientiousness $d=$

0.08 [-0.72, 0.93]

(NS)

2b. Amplitude ALI 0.8

$\mathrm{Hz}$ : 
Agreeableness $d=$ $0.10[-0.72,0.93]$ (NS),

openness $d=0.04$ [$0.77,0.87]$ (NS),

extraversion $d=0.24$

$[-0.58,1.09]$ (NS),

neuroticism $d=1.22$ [-

$0.17,2.27]$ (sig)

conscientiousness $d=$ $0.28[-0.54,1.12]$ (NS).

2c. Amplitude ITPC $0.8 \mathrm{~Hz}$

Agreeableness $d=$ $0.36[-0.45,1.22]$ (NS),

openness $d=0.85$ [0.02, 1.81] (NS),

extraversion $d=-0.37$

$[-1.22,0.45]$ (NS),

neuroticism $d=-0.43$

$[-1.32,0.37]$ (NS),

conscientiousness $d=$

$-0.02[-0.85,0.80]$

(NS).

2d. Phase delay ITPC:

Agreeableness $d=$

$0.16[-0.65,1.01]$

$$
\text { (NS), }
$$

openness $d=0.18$ [$0.63,1.01]$ (NS),

extraversion $d=0.18$

[-0.63, 1.01] (NS),

neuroticism $d=-0.65$

$[-1.58,0.16]$ (Sig),

conscientiousness $d=$

$0.08[-0.75,0.93]$

(NS). 
Weis et al. (2013)

(2013)

\section{Zekveld et 63 (34 \\ al. (2019) NH;29 \\ HI)}
Interfering speech
masker - male
speaker. SRT50\%
and SRT71\%
conditions.

Reward session - gain low (€0.10) or high

$(€ 0.50)$ reward for correct answers. Punishment session - start with €25 and lose either a low $(€ 0.10)$ or high (€0.50) amount for incorrect

1. \% correct

2. RTs

3. fMRl during

reinforcement

period

$$
\text { answers. }
$$

Social-evaluative threat
(impossible to reach
target).

\section{SRT50 \\ 2. BPD \\ 3. PPD}

4. MPD

5a. SR effort

5b. SR giving up
1. NS effect of type of session

(reward/punishment),

NS effect of value, NS

session/value

interaction for \%

$$
\text { correct. }
$$

2. Sig session/reward

interaction for RTs:

punishment session $d$

$=0.24$ [-0.21, 0.69];

reward session $d=$ -

$0.08[-0.53,0.37]$

3. NS effects of

reward value for

BOLD response in

auditory cortex

Higher BOLD

response for high versus low

reinforcement in the right and left visual cortex, anterior

cingulate cortex and right insular.

1. NS effect of

evaluative threat for SRT50: NH $d=-0.16$, $[-0.49,0.18], \mathrm{HI} d=$ $0.16[-0.21,0.52]$. 2. NS main or interaction effects for BPD: $\mathrm{NH}$ at SRT50 $d$ $=-0.02[-0.70,0.65]$, $\mathrm{HI}$ at SRT50 $d=0.32$ $[-0.41,1.06]$

3. Sig main effect of 
feedback group on PPD:

$\mathrm{NH}$ at SRT50 $d=0.10$

[-0.57, 0.77],

$\mathrm{HI}$ at SRT50 $d=0.12$

$[-0.61,0.85]$

4. NS main effect of evaluative threat

group or interactions for MPD:

$\mathrm{NH}$ at SRT50 $d=0.10$ [-0.57, 0.77],

$\mathrm{HI}$ at SRT50 $d=0.15$ $[-0.58,0.88]$

5a. Sig main effect of evaluative threat on SR effort

$\mathrm{NH} d=1.16[0.43$, 1.89],

$\mathrm{HI} d=0.84$ [0.07,

$$
\text { 1.60]. }
$$

5b. Sig main effect of evaluative threat on SR giving up: $\mathrm{NH} d=0.82$ [0.11,

$$
\text { 1.51], }
$$

$\mathrm{HI} d=2.50$ [1.50, 3.47].

Speech rate (slow, normal, slightly fast, fast, extremely fast)
Reward point value of each sentence $(1,3,5,7$ or 9) (1000 points needed to receive reward). NFCog

(Covariate). 1a. Correlation between effort efficiency and NFCog score 1b. Correlation between performance accuracy and NFCog score 1a. Sig negative correlation between effort efficiency and NFCog $d=-0.88[-$ $1.52,-0.24]$.

1b. NS correlation between performance accuracy and NFCog $d=-0.08[-0.55,0.39]$. 
Speech rate (slow, normal, slightly fast, fast, extremely fast)
Reward point value of each sentence $(1,3,5,7$ or 9$)$ (1000 points needed to receive reward).
1. Accuracy 2. PPD:

a. cue window

2b. sentence presentation

2c. response window
1. Sig reward/speech rate interaction for

task accuracy $d=0.26$

$[-0.06,0.58]$.

2a. Sig effect of

reward on PPD in cue

window $d=0.53[0.2$, $0.86]$.

2b. Sig effect of

reward on PPD during sentence presentation

$d=0.52$ [0.19, 0.85]

NS reward*demand

interaction for PPD $d=$

0.08 [-0.23, 0.39].

2c. Sig

demand ${ }^{*}$ reward

interaction for PPD

during response

window $d=0.48[0.15$ $0.81]$.

\footnotetext{
Note: ? - not stated, 16PFQ = Sixteen Personality Factor Questionnaire, ALI = alpha lateralisation index, AMI = attentional modulation index, BA = Brodmann

area, BOLD response = blood oxygenation level dependent response, BPD = baseline pupil diameter, CSCT = Cognitive Spare Capacity Test, DBP =

diastolic blood pressure, EEG = electroencephalogram, EMG = electromyography, EPQ = Eysenck Personality Questionnaire, ERPs = event related

potentials, $\mathrm{fMRI}=$ functional magnetic resonance imaging, $\mathrm{HA}=$ participants with hearing aids, $\mathrm{HI}=$ participants with hearing impairment, $\mathrm{HR}=$ heart rate,

ITPC = intertribal phase coherence, MBTI = Myers-Briggs Type Indicator, MPD = mean pupil diameter, N1 = negative ERP component (peak between 80 and

120 ms after stimulus onset), N2 = negative ERP component (peak between 200 and 300 ms after stimulus onset, NASA-TLX = NASA Task Load Index, NS

$=$ non-significant, NFCog $=$ Need for Cognition, $\mathrm{NH}=$ normal hearing participants, P3 = positive ERP component (peak between 250 and 500 ms after

stimulus onset), PEP = pre-ejection period, PPD = peak pupil diameter, $\mathrm{Pz}=$ midline parietal electrode, $\mathrm{RT}=\mathrm{reaction}$ time, $\mathrm{SBP}=\mathrm{systolic}$ blood pressure, Sig

= significant, SNR= signal-to-noise ratio, SR = self-rated, SRT = Speech reception threshold, wpm = words per minute.
} 
Table 3. Meta-Analysis of the effects of motivational factors on all LE outcome measurements.

\begin{tabular}{|c|c|c|c|c|c|c|c|}
\hline $\begin{array}{c}\mathrm{LE} \\
\text { Outcome }\end{array}$ & Subgroup & $\begin{array}{l}\text { \# of outcomes } \\
\text { (contributing } \\
\text { studies) }\end{array}$ & $\begin{array}{c}\text { Pooled } \\
\text { sample } \\
\text { size }\end{array}$ & $\begin{array}{c}\text { Effect size } \\
(\mathrm{SMD}) \\
95 \% \mathrm{Cl}\end{array}$ & $\begin{array}{c}\text { Z-statistic } \\
\boldsymbol{p} \text {-value }\end{array}$ & $T^{2}$ & $\begin{array}{c}\text { Prediction } \\
\text { interval }\end{array}$ \\
\hline \multicolumn{8}{|c|}{ Subgroup analysis $\mathrm{A}$ : Comparison of extrinsic manipulations of motivation $(\mathrm{k}=184)(Q(3)=11.91, p=.008) \mathrm{PI}=[-.31,1.00]^{]}$} \\
\hline All & Financial reward & $44(16)$ & 1046 & $0.40^{\star \star}[0.28,0.52]$ & $6.30(<.001)$ & $67.2[55.1,76.0]$ & {$[-.29,1.09]$} \\
\hline All & Evaluative threat & $23(3)$ & 574 & $\mathbf{0 . 4 3 ^ { \star \star }}[0.27,0.61]$ & $5.01 \quad(<.001)$ & $47.3[14.2,67.6]$ & {$[-.18,1.06]$} \\
\hline All & Perceived competence & $12(5)$ & 769 & $\mathbf{0 . 6 7 ^ { * * }}[0.42,0.92]$ & $5.22(<.001)$ & $62.9[30.9,80.1]$ & {$[-.14,1.48]$} \\
\hline All & Individual traits & $105(18)$ & 5431 & $\mathbf{0 . 2 7 ^ { \star \star }}[0.19,0.34]$ & $7.09(<.001)$ & 68.8 [61.9 74.4] & {$[-.29,1.09]$} \\
\hline
\end{tabular}

Bold and ${ }^{*} p<.05,{ }^{* *} p<.001$. Note that some studies contribute outcomes to multiple groups. Feedback is not included in this analysis because of insufficient number of outcomes in the included studies. 
Table 4. Post-hoc tests for subgroup analysis A, averaged over all types of LE outcome measurements.

\begin{tabular}{cccc}
\hline LE & Post-hoc test & Q-statistic & $p$-value \\
\hline Outcome & Financial reward / Evaluative threat & 0.14 & .711 \\
All & Financial reward / Perceived competence & 3.55 & .059 \\
All & Financial reward / Individual traits & 2.97 & .084 \\
All & Evaluative threat / Perceived competence & 2.18 & .140 \\
All & Evaluative threat / Individual traits & 3.07 & .080 \\
All & Perceived competence / Individual traits & 8.81 &. $\mathbf{0 0 3}^{*}$ \\
All & * and bold $p<$.007 (adjusted alpha level for number of comparisons)
\end{tabular}

${ }^{*}$ and bold $p<.007$ (adjusted alpha level for number of comparisons). 
Table 5. Subgroup analyses investigating the influence of LE outcome measurement on the relationship between motivational factors and LE.

\begin{tabular}{|c|c|c|c|c|c|c|c|}
\hline $\begin{array}{c}\text { LE } \\
\text { Outcome }\end{array}$ & Subgroup & $\begin{array}{c}\text { \# of outcomes } \\
\text { (contributing } \\
\text { studies) }\end{array}$ & $\begin{array}{l}\text { Pooled } \\
\text { sample } \\
\text { size }\end{array}$ & $\begin{array}{c}\text { Effect size } \\
\text { (SMD) } \\
95 \% \mathrm{Cl}\end{array}$ & $\begin{array}{c}\text { Z-statistic } \\
p \text {-value }\end{array}$ & $F^{2}$ & $\begin{array}{l}\text { Prediction } \\
\text { interval }\end{array}$ \\
\hline \multicolumn{8}{|c|}{ Subgroup analysis B: Comparison of LE outcome measurement for all motivational factors $(\mathrm{k}=187)(Q(2)=1.92, p=.383, \mathrm{PI}=[-.30, .99])$} \\
\hline Behavioural & - & $70(30)$ & 3756 & $\mathbf{0 . 2 9} \mathbf{9}^{\star \star}[0.20,0.39]$ & $5.94(<.001)$ & $72.4[65.0,78.2]$ & {$[-.38,0.97]$} \\
\hline Physiological & - & $99(24)$ & 3536 & $\mathbf{0 . 3 7 ^ { \star \star }}[0.29,0.45]$ & $8.99(<.001)$ & $63.7[55.0,70.7]$ & {$[-. .26,1.00]$} \\
\hline Subjective & - & $18(6)$ & 600 & $0.42^{\star \star}[0.20,0.64]$ & $3.78(<.001)$ & $70.2[51.8,81.6]$ & {$[-.42,1.27]$} \\
\hline \multicolumn{8}{|c|}{ Subgroup analysis C: Effects of all motivational factors on behavioural LE outcomes $(\mathrm{k}=74)$ by type $(Q(1)=0.01, p=.911, \mathrm{PI}=[-.38, .97])$} \\
\hline Behavioural & Performance accuracy & $55(28)$ & 2969 & $0.29^{\star \star}[0.18,0.41]$ & $5.03(<.001)$ & $73.6[65.7,79.7]$ & {$[-.43,1.01]$} \\
\hline Behavioural & RTs & $15(10)$ & 787 & $0.30^{\star *}[0.13,0.48]$ & $3.41(<.001)$ & $65.2[39.7,79.9]$ & {$[-.30, .91]$} \\
\hline \multicolumn{8}{|c|}{ Subgroup analysis D: Effects of all motivational factors on physiological LE outcomes $(\mathrm{k}=91)$ by type $(Q(1)=0.11, p=.743, \mathrm{PI}=[-.24, .92])$} \\
\hline Physiological & EEG & $70(12)$ & 2577 & $0.35^{\star \star}[0.26,0.44]$ & $7.29(<.001)$ & $61.6[50.2,70.3]$ & {$[-.27, .97]$} \\
\hline Physiological & Pupillometry & $21(8)$ & 758 & $\mathbf{0 . 3 2} 2^{\star \star}[0.17,0.47]$ & $4.26(<.001)$ & $55.5[27.2,72.7]$ & {$[-.21, .85]$} \\
\hline
\end{tabular}

Bold and ${ }^{*} p<.05,{ }^{* *} p<.001$. Note that some studies contribute outcomes to multiple groups. 
Table 6. Meta-analysis of effects of combining different motivational factors with different types of LE outcome measurements.

\begin{tabular}{|c|c|c|c|c|c|c|c|}
\hline $\begin{array}{c}\text { LE } \\
\text { Outcome }\end{array}$ & Subgroup & $\begin{array}{c}\text { \# of outcomes } \\
\text { (contributing } \\
\text { studies) }\end{array}$ & $\begin{array}{l}\text { Pooled } \\
\text { sample } \\
\text { size }\end{array}$ & $\begin{array}{c}\text { Effect size } \\
\text { (SMD) } \\
95 \% \mathrm{Cl}\end{array}$ & $\begin{array}{c}\text { Z-statistic } \\
p \text {-value }\end{array}$ & $F^{2}$ & $\begin{array}{c}\text { Prediction } \\
\text { interval }\end{array}$ \\
\hline \multicolumn{8}{|c|}{ Subgroup analysis E: Effects of financial reward on LE $(\mathrm{k}=44)$ by outcome type $(Q(2)=9.53, p=.009, \mathrm{PI}=[-.29,1.09])^{\star}$} \\
\hline Behavioural & Financial reward & $21(12)$ & 460 & $0.34^{\star \star}[0.16,0.52]$ & $3.66(<.001)$ & $67.3[48.5,79.3]$ & {$[-.39,1.06]$} \\
\hline Physiological & Financial reward & $17(9)$ & 430 & $0.58^{\star \star}[0.37,0.80]$ & $5.35(<.001)$ & $72.5[55.4,83.1]$ & {$[-.24,1.41]$} \\
\hline Subjective & Financial reward & $6(3)$ & 156 & $0.11^{*}[-0.10,0.32]$ & $1.05(0.03)$ & $0[0,0]$ & {$[-.19, .41]$} \\
\hline \multicolumn{8}{|c|}{ Subgroup analysis $\mathrm{F}$ : Effects of individual traits on $\mathrm{LE}(\mathrm{k}=103)$ by outcome type $(Q(1)=5.91, p=.02, \mathrm{PI}=[-.34, .89])^{*}$} \\
\hline Behavioural & Individual traits & $33(11)$ & 2420 & $0.15^{\star}[0.03,0.27]$ & $2.46(.014)$ & $71.1[58.9,79.6]$ & {$[-.44, .74]$} \\
\hline Physiological & Individual traits & $70(13)$ & 2789 & $0.34^{\star \star}[0.25,0.44]$ & $7.05(<.001)$ & $64.0[53.5,72.1]$ & {$[-.29, .98]$} \\
\hline \multicolumn{8}{|c|}{ Subgroup analysis G: Effects of evaluative threat on LE $(\mathrm{k}=22)$ by outcome type $(Q(1)=7.42, p=.006, \mathrm{PI}=[-.16,1.01])^{\star}$} \\
\hline Physiological & Evaluative threat & $10(2)$ & 269 & $0.24^{\star}[0.07,0.38]$ & $2.88(.004)$ & $0[0,34.0]$ & {$[-.18, .65]$} \\
\hline Subjective & Evaluative threat & $10(2)$ & 222 & $\mathbf{0 . 7 2} 2^{\star \star}[0.43,1.01]$ & $1.61(<.001)$ & $55.2[8.7,78.0]$ & {$[-.15,1.59]$} \\
\hline
\end{tabular}

Bold and ${ }^{*} p<.05,{ }^{* *} p<.001$. Note that some studies contribute outcomes to multiple groups. 
Table 7. Post-hoc tests for subgroup analysis $\mathrm{E}$.

\begin{tabular}{|c|c|c|c|}
\hline $\begin{array}{l}\text { Motivational } \\
\text { factor }\end{array}$ & Post-hoc test & Q-statistic & $p$-value \\
\hline $\begin{array}{l}\text { Financial } \\
\text { reward }\end{array}$ & Behavioural/Physiological & 2.98 & .084 \\
\hline $\begin{array}{l}\text { Financial } \\
\text { reward }\end{array}$ & Behavioural/Subjective & 2.54 & .110 \\
\hline $\begin{array}{c}\text { Financial } \\
\text { reward }\end{array}$ & Physiological/Subjective & 9.53 & $.002^{\star}$ \\
\hline
\end{tabular}

* and bold $p<.017$ (adjusted alpha level for number of comparisons). 

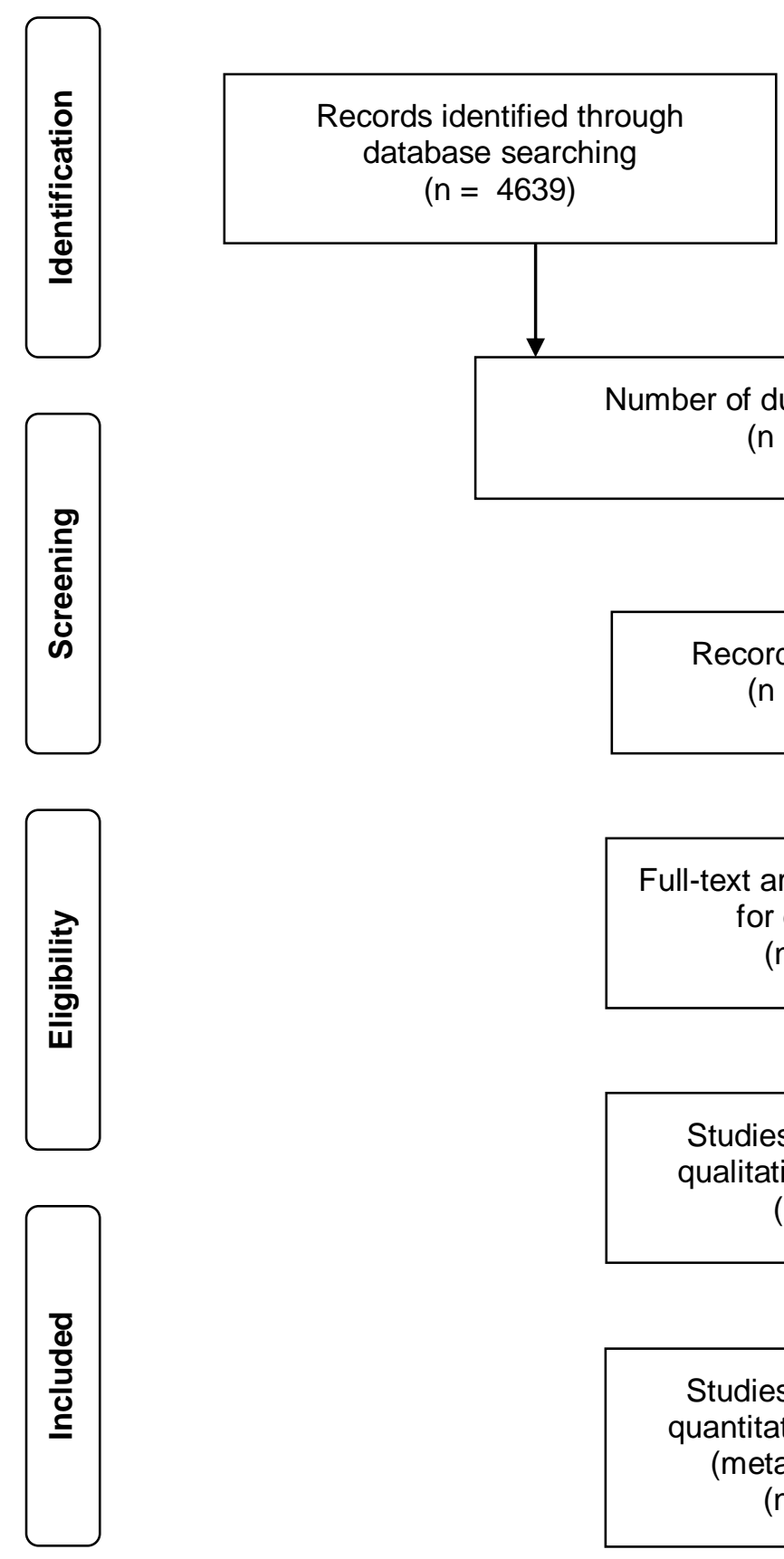

Additional records identified through other sources

$(n=28)$
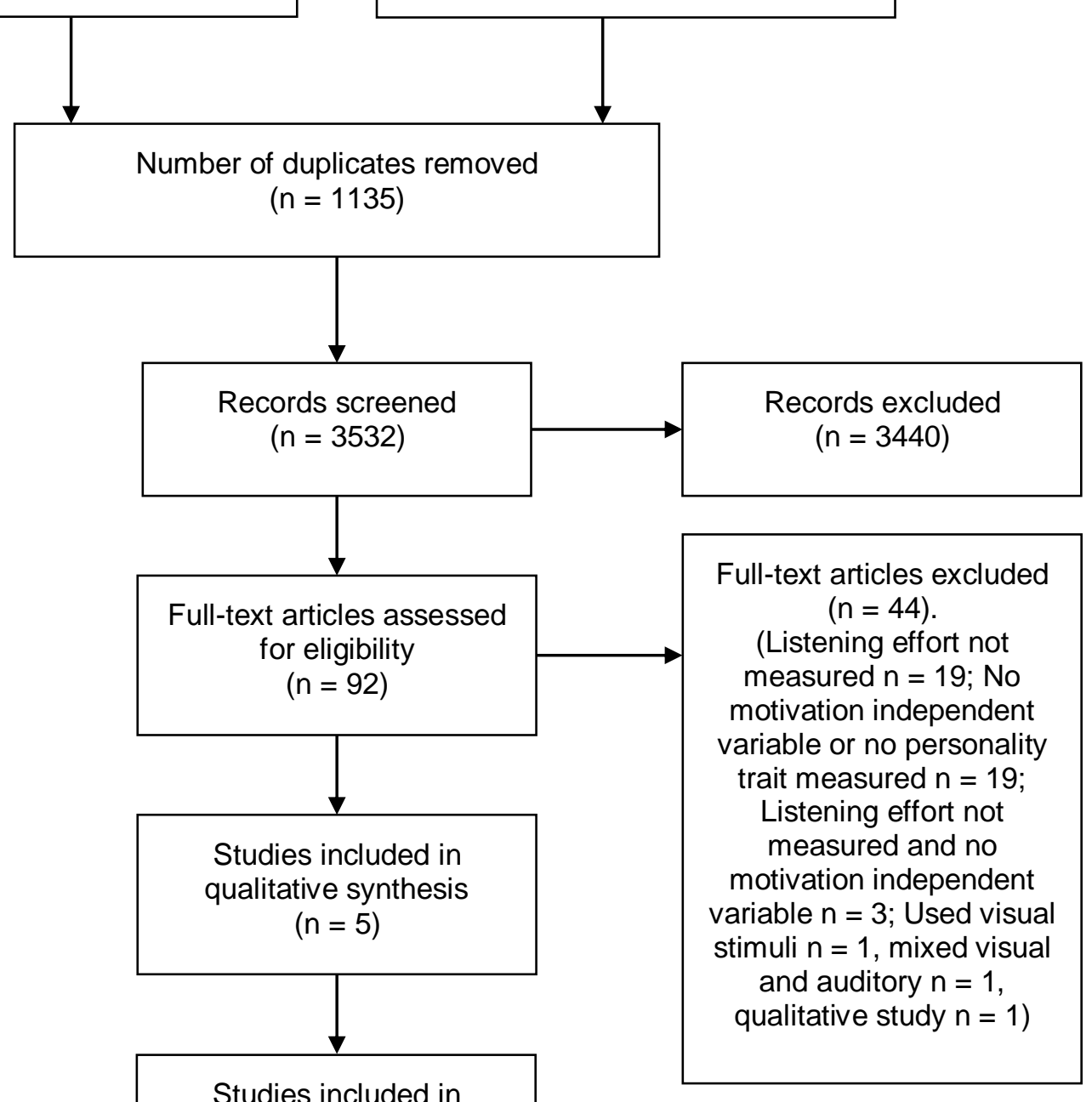

quantitative synthesis

(meta-analysis)

$(n=43)$

Figure 1. PRISMA flowchart showing the identification, screening, eligibility and inclusion phases of the literature search. 


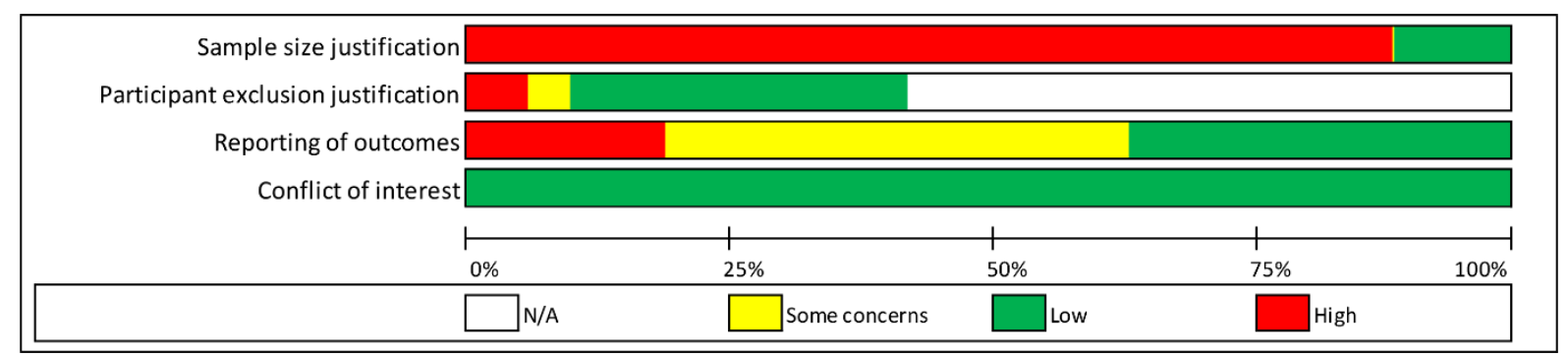

Figure 2. Summary of risk of bias scores for all included studies. Full details of the scoring questions and descriptions of the response categories are in Table S1. Q1: Did the authors include a sample size justification? Q2: If any participant data is excluded from the analysis is a clear justification given? Q3: Were all the outcome measures in the methods included in the results? Q4: Were there any conflicts of interest? Overall percentage scores were calculated for each level of bias, with green indicating low bias, yellow some concerns, red high and white not-applicable. 


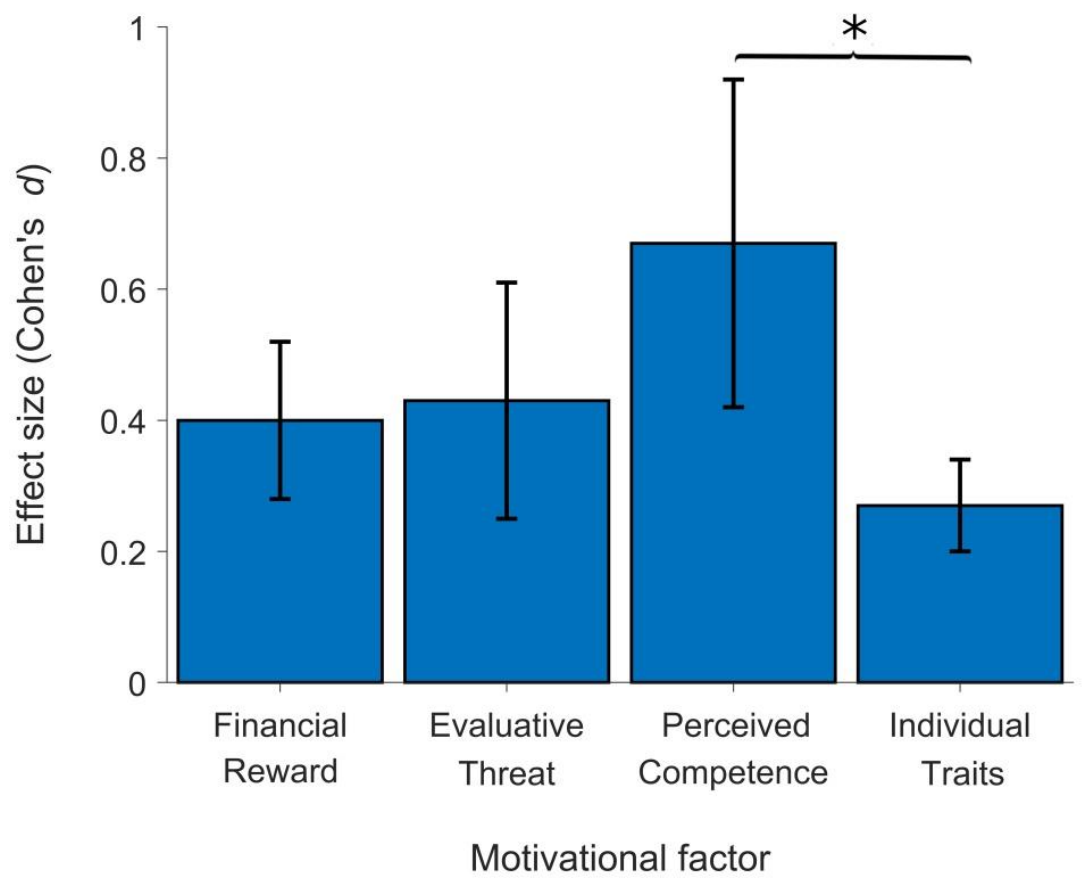

Figure 3. Effect sizes (Cohen's $d$ ) for the influence of specific motivational factors on listening effort (Cohen's d). Error bars represent 95\% confidence intervals for the effect size. Perceived competence had a significantly larger effect compared to individual traits $(p<.007)$. 


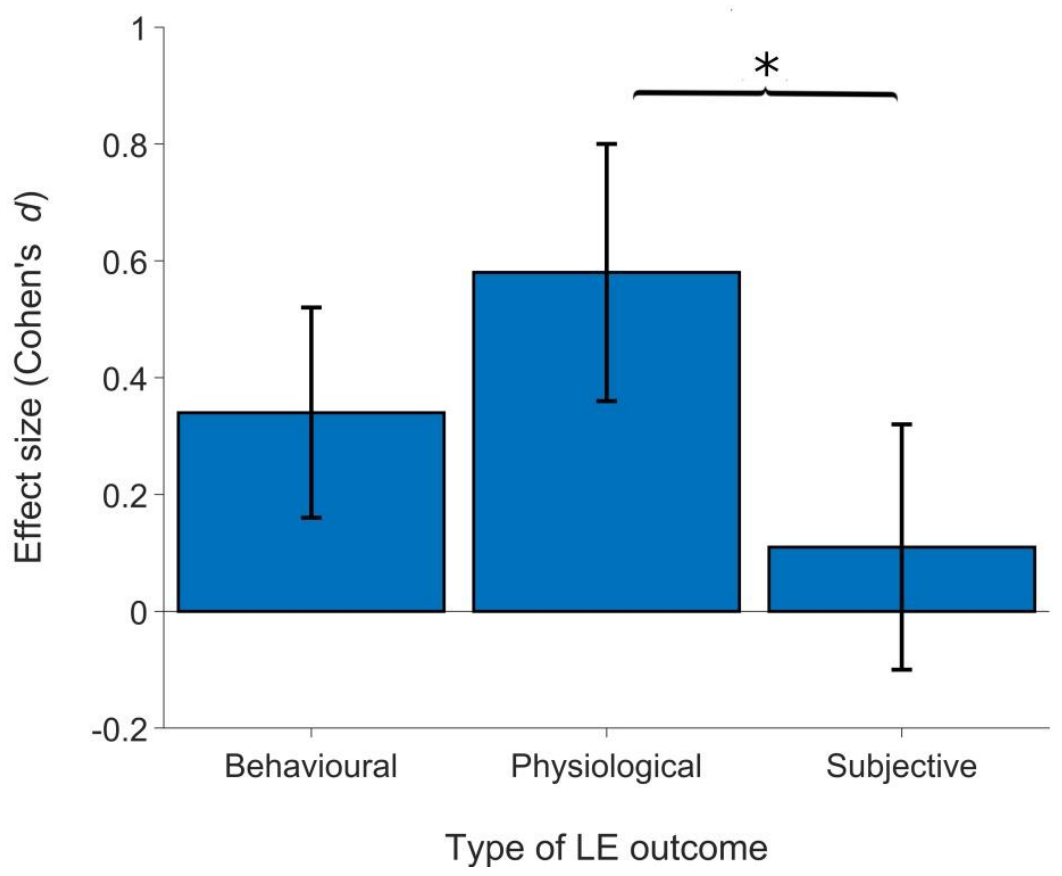

Figure 4. Effect sizes (Cohen's $d$ ) measured using different types of LE outcome measurements when motivation is operationalised as financial reward. Error bars represent $95 \%$ confidence intervals for the effect size. Physiological measures indexed significantly larger effects compared to subjective measures of LE $(p<.017)$. 